\title{
Research Paper \\ Development of the Draft of Law (Mental Health Act)
}

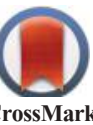

Mehdi Nasr Esfahani ${ }^{1,2^{*}}$, Jafar Attari Moghadam ${ }^{3}$

1. Psychiatrist, Rasool Akram Hospital, Iran University of Medical Sciences, Tehran, Iran.

2. Associate Professor, Mental Health Research Center, School of Behavioral Sciences and Mental Health (Tehran Institute of Psychiatry), Iran University of Medical Sciences, Tehran, Iran.

3. Psychiatrist, Central Petroleum Hospital, Tehran, Iran.

$\begin{gathered}\text { Use your device to scan } \\ \text { and read the article online }\end{gathered}$
Citation: Nasr Esfahani M, Attari Moghadam J. [Development of the Draft of Law (Mental Health Act) (Persian)]. Iranian
Journal of Psychiatry and Clinical Psychology. 2017; 23(1):50-67. https://doi.org/10.18869/NIRP.IJPCP.23.1.50

Received: 02 Aug. 2016

Accepted: 20 Dec. 2016

Key words:

Mental health act,

Iran, Involuntary

hospitalization,

Criminal patient,

Guardianship

\begin{abstract}
AB STRACT
Objectives Mental health acts have been developed in different countries to protect human and civil rights of people with psychiatric disorders. In Iran, although there are some scattered laws within the existing body of laws, there is no separate mental health act. The aim of the present project was to prepare a draft pertaining to the mental health act in the country.

Methods The draft of the mental health act was developed over three stages. In the first stage, the authors reviewed the existing literature on domestic and foreign codified laws. Thereafter, the selection procedure of one mental health act, which seemed more complete and thorough as a model and guide, took place. Then, various issues were discussed from different vantage points in group sessions; and finally, keeping in mind the cultural aspects, the first draft of the act was prepared. The draft was sent to a number of mental health experts, organizations, governmental and non-governmental institutions, and their views were summarized and categorized. Following that, the disputed issues were presented at a national workshop in which various experts and stakeholders participated. Their opinions were summed up and the initial draft was finalized. In the second stage, at the Center for Ethics and History of Medicine, where a number of lawyers participated, the draft was converted into the form of legal codes (articles) and like the first stage, the opinions of legal experts, judicial authorities and a large number of universities, governmental and non-governmental organizations were obtained. In order to make the final decision, the conflicting views were addressed at a second national workshop, where the final corrections were made, and the draft spanning 10 chapters and 112 articles was prepared. In the third stage, considering the suggestion of the legal office of the Ministry of Health, Treatment and Medical Education, the prepared text was revised and the draft was condensed into 50 articles.

Results The first draft of the mental health act was developed over 8 years and included six chapters and 50 articles. The draft includes chapters on Definitions, Hospitalization, Involuntary Treatment, Special Treatment Methods, special groups, and other provisions.
\end{abstract}

\section{Extended Abstract}

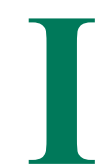

\section{Introduction}

$\mathrm{n}$ many parts of the world, people afflicted with psychiatric disorders belong to the community of socially vulnerable people. In addition to the obvious suffering caused by mental disorders, these people face burnout resulting from the stigma associated with mental disorder and separation from society. Unfortunately, they are neglected and suffer from sexual-phys-

……

* Corresponding Author:

Mehdi Nasr Esfahani, MD

Address: Mental Health Research Center, Iran University of Medical Sciences, Tehran, Iran.

Tel: +98 (21) 88512143

E-mail: mehdinassr@gmail.com 
ical and psychological abuse. In addition, they deal with the prospect of losing their jobs and obtaining access to services.

With regard to patients with mental frailties, Iran has accorded them with more dignity in comparison with the rest of the world. Mental health laws in countries have been developed to protect the human and civil rights of people with mental disorders. In Iran, although there are laws sporadically in the collection of existing laws, there is no separate mental health legislation. The aim of this project was to develop a draft of mental health law in Iran.

\section{Method}

The draft law on mental health has been developed over three phases. In the first phase, people responsible for drafting reviewed the resources about domestic and foreign codified law and selected, among other countries, the most comprehensive mental health legislation as an example and guide. Thereafter, various subjects were mentioned in group meetings with respect to various aspects of the debate and finally, keeping cultural aspects in mind, the initial draft was prepared. The draft was sent to a large number of mental health professionals, government agencies, and non-governmental organizations, and their views were collected and classified. Then, the areas of conflict were discussed in a national workshop attended by experts and stakeholders. Their views were summarized, and the final draft was edited. In the second stage, the written material of the draft became law in Ethics and History of Medicine Research Center in the presence of some lawyers. Like the first stage, the comments of legal experts, a large number of academic centers, governmental and nongovernmental organizations were collected. For a final decision, inconsistent comments were mentioned in the country second workshop and the last reforms applied and the draft was finalized on 10 chapters and 112 articles. In the third stage, acting upon the suggestion from the legal office of the Ministry of Health and Medical Education, the text prepared was revised and the draft summarized across six chapters and 50 articles.

\section{Results}

Finally, after 27 sessions of 4 hours duration each, the draft of the Mental Health Law was codified with an article as an introduction and six chapters comprising a total of 50 articles. Draft chapters included the first chapter, titled Definitions, which had 1 article and 18 clauses. The second chapter titled Involuntary Hospitalization and Treatment had 11 articles while the third chapter titled Specific Methods of Treatment had 7 articles. The fourth chapter titled Punitive Patient had six articles, and the fifth chapter titled Special Groups had 4 articles. The sixth chapter titled Other Provisions had 20 articles. In the end, the fifth edition of the draft law was developed.

In the first chapter, all terms used were defined in the draft law including severe mental disorder, psychological crisis, compulsory community treatment, serious injury, severe mental disorder and involuntary hospitalization. The second chapter is devoted to involuntary hospitalization and treatment. The third chapter concerns specific methods of treatment. In this chapter, legal provisions related to compulsory community treatment, therapy, restrain, isolation or detention were provided. The fourth chapter is related to criminal cases. In addition to taking into account the expert aspects of subject matter, in the provisions of this chapter the rights of these patients have also been considered. The fifth chapter is about the special groups. According to the law, these groups are referred to as certain groups of people under 18 and over 65 years of age as well as those who, for any reason, are unable to manage their financial affairs. Chapter six is about the development of insurance services, establishing judicial hospitals and penalties for violators of the law. From the beginning till the development of the fifth edition, this plan consumed 18,000 man-hours.

\section{Discussion}

Finally, after intensive work group with experts in the field of Medicine, Psychology, Law, conducting two large surveys with the help of experts, and organizing two workshops in the country, the draft pertaining to the Mental Health Law was developed. The various chapters of the draft, especially the ones which deal with the loss of patients' rights such as Involuntary Hospitalization, Compulsory Treatment, Punitive Patients or Special Patient Groups, were developed in such a way that patients' rights be respected as much as possible. In this respect, the content of this draft is similar to a lot of mental health laws existing in developed countries [18-22].

In addition to the presence of a system of independent assessment within the draft, at all stages of involuntary hospitalization and treatment, the right of a person to protest was considered as was the way in which the protests were to be handled. The methods, mentioned in this draft, used for involuntary hospitalization are to a certain extent similar to the ones used in other countries [26]. Despite the similarities, there are differences as well. In this draft, the aspects of cultural and social structures were considered. For example, the drafters tried to develop a document which would not only be applicable to the existing 
organizational structures but also aid in the development of such structures. The draft was, however, less comprehensive in comparison with the mental health regulations of some developed countries [18, 20].

Although it cannot be claimed that the draft developed is devoid of any shortcomings, but it is, with no doubt, one draft law that has been developed and prepared in conjunction with the greatest number of experts in the legislation and codification history of Iran. The major constraint that arose in the development of this draft was the lack of comments from patients and their families which originally should be administered to them after the adoption of the law. The prepared draft cannot be invoked in any way and must be approved by the Parliament.

\section{Acknowledgments}

Office of the Mental-Social Health, and Addiction at the Ministry of Health and Medical Education, and School of Behavioral Sciences and Mental Health (Tehran Institute of Psychiatry), Iran University of Medical Sciences, Tehran, Iran, have financially supported the present paper.

\section{Conflict of Interests}

The authors declared no conflicts of interest. 


\title{
تدوين ييشنويس قانون سلامت روان
}

\author{
"مهدى نصر اصفهانى" "م، جعر عطارى مقدم"

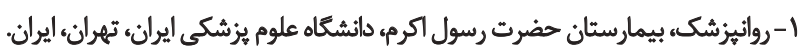

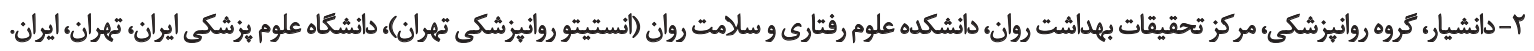

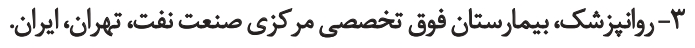

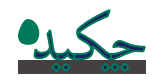

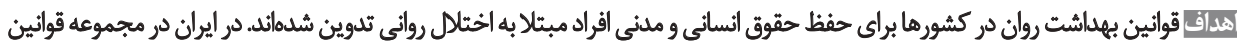

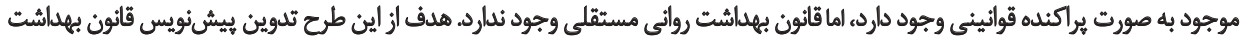
روان در ايران الست.

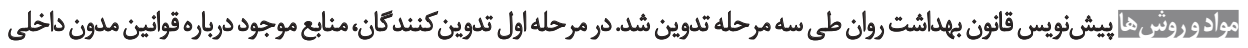

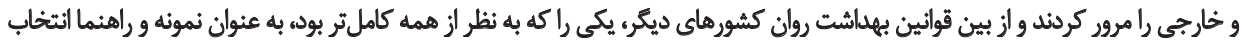

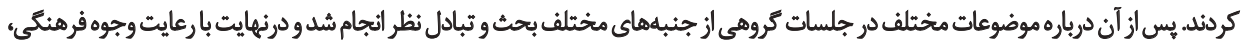

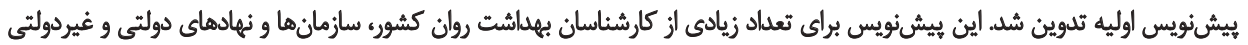

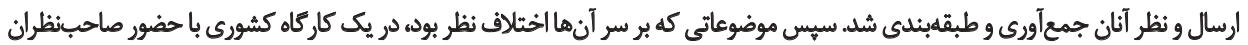

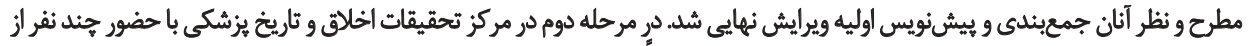

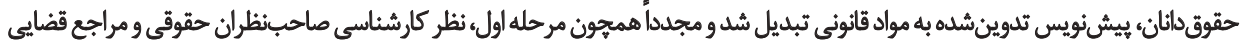

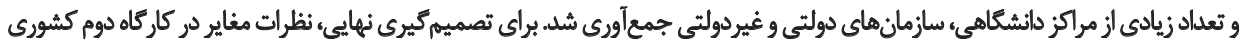

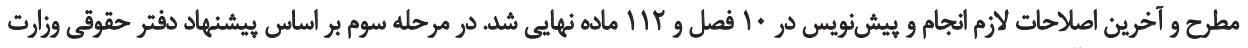

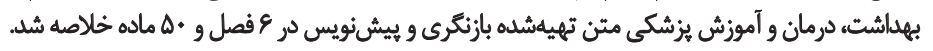

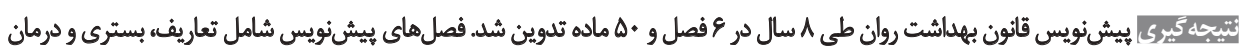

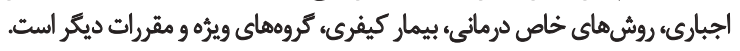

تاريخ دريافت: TIا مرداد

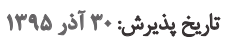

كليدوارثها:

قانون بهداشت روان، ايران،

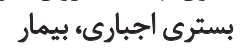

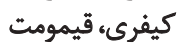

$$
\text { تصميم گيرى قلمداد ميشوند. }
$$

dato

از طرف ديكر كاهى نيز خطرناكبودن به كل بيماران تعميم

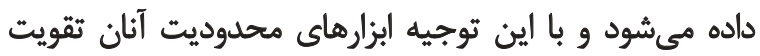

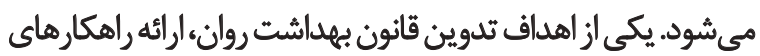

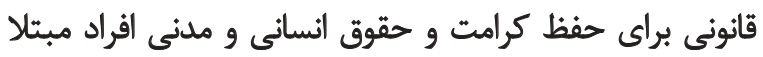

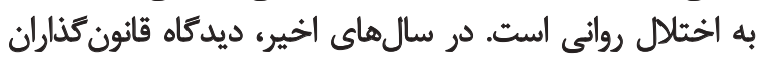

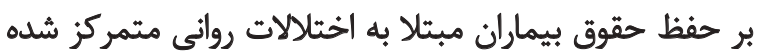

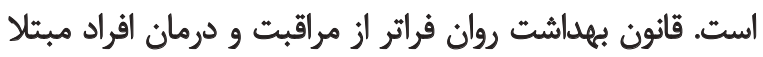

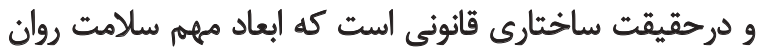

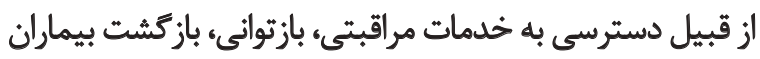

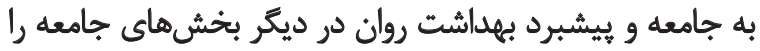

شامل مىشود [1] [1].

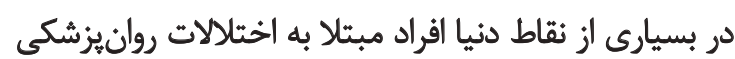

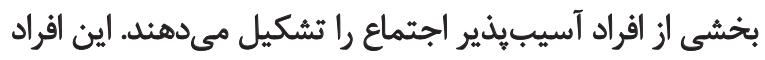

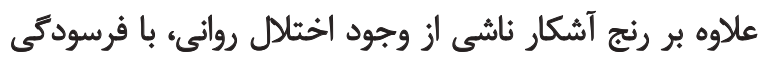

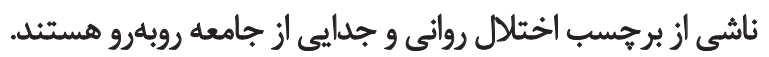

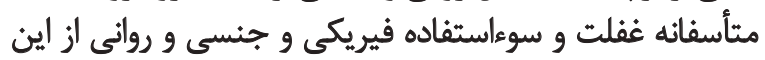

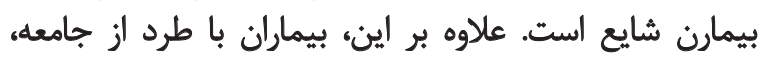

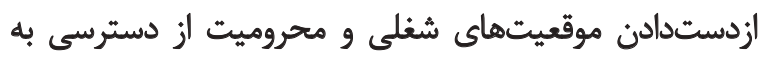

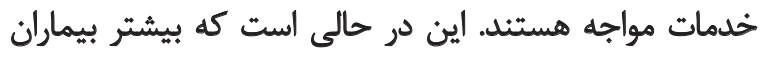

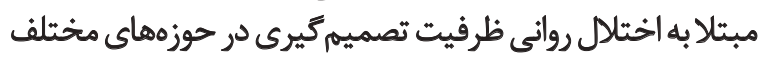

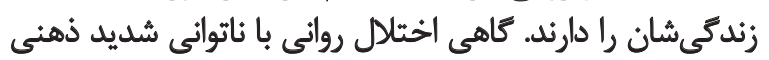

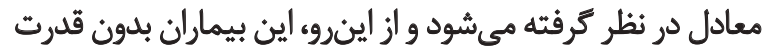


در سال 1999 سازمان جهانى بهداشت سندى منتشر كرد كه

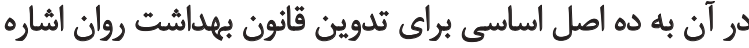

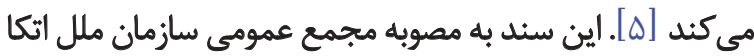

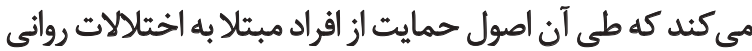

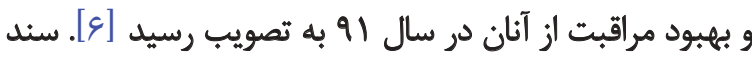

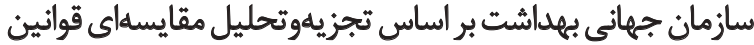

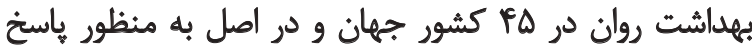

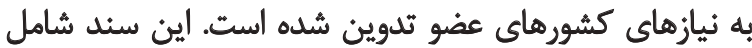

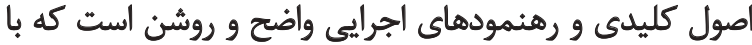
هدف تشريح اصول اساسى قانون براي بهداشت روائ روان و وبا حداقل

تأثيريذيرى از فرهنكى خاص تنظيم شده است [هـ].

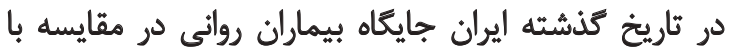

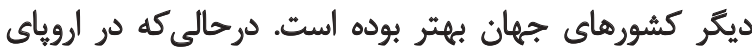

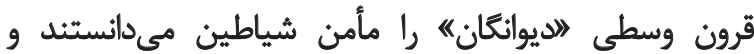

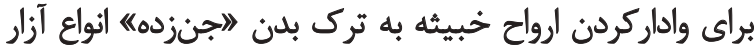

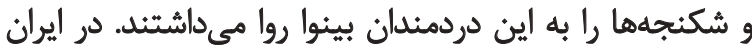

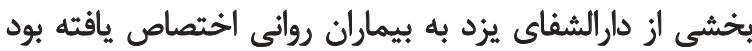

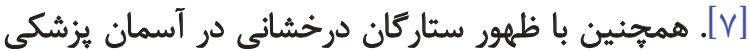

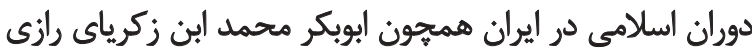

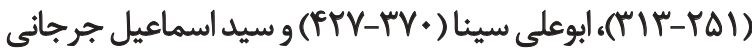

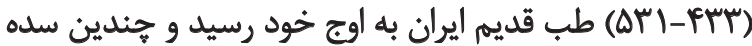

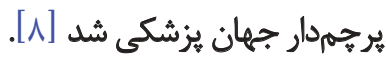

مطالعه آثار اين بزركان بهخوبى نشان ميدهد كه رويكردى

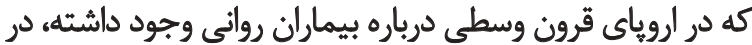

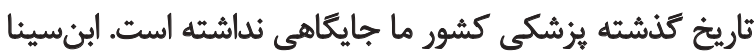

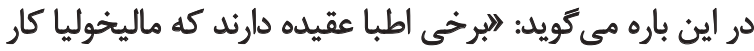

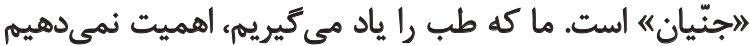

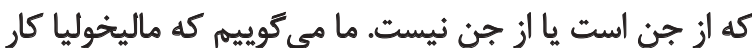

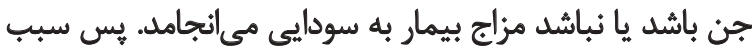

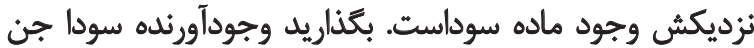

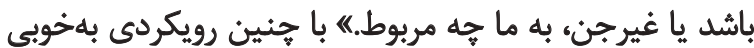

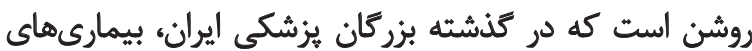

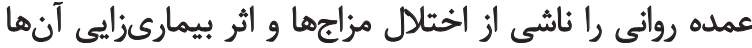

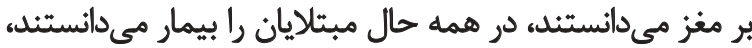

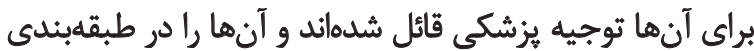

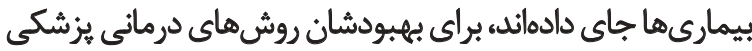

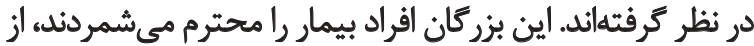

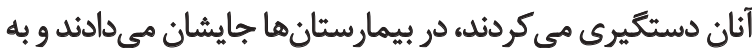

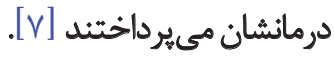

بدون ترديد در آن روزكار، انديشهها و اعتقادات مذهبي اين

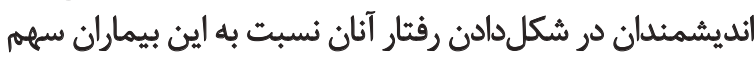

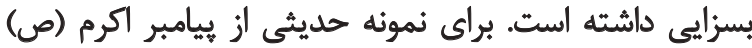

سازمان جهاني بهداشت در سال $19 \Delta \Delta$ در كشورهايي كه براي

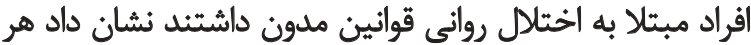

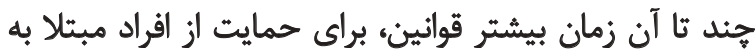

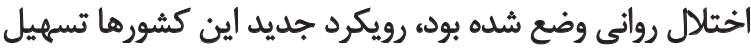

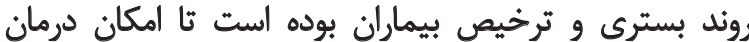

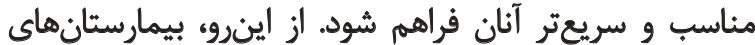

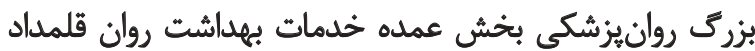

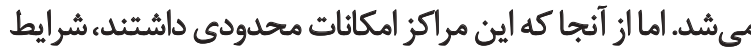

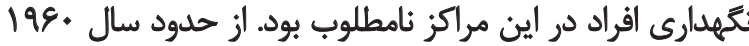

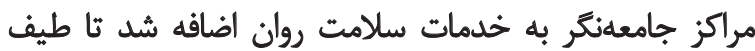

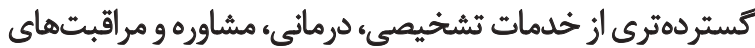

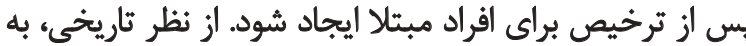

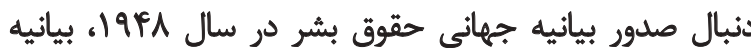

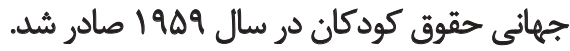

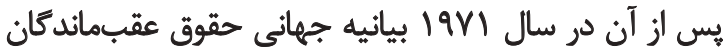

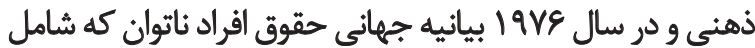

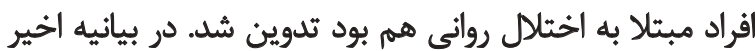

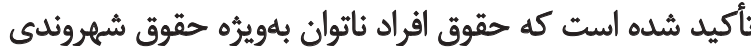

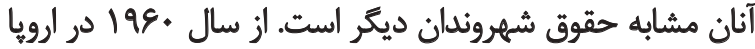

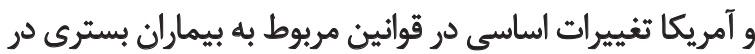

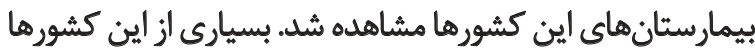

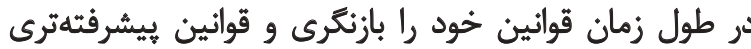

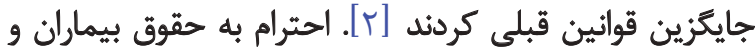

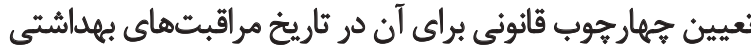
و درمانى كشورها سوابق طولاتى دارد.

كانون بهداشت روان شامل مقرراتى است كه براى حمايت و وراني كنترل افراد بيمار، ساماندهى بسترى اجبارى، فرايند تجرئ تجديد

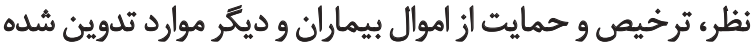

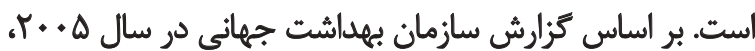

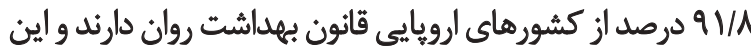

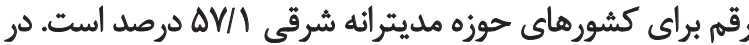

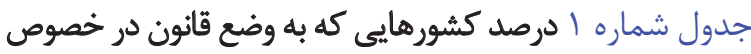

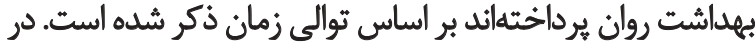

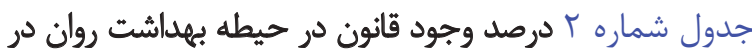

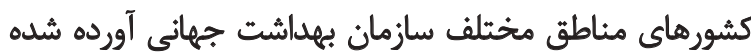

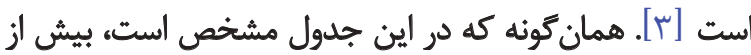

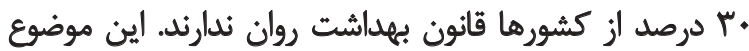

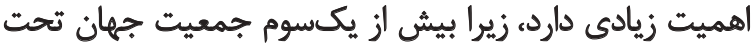

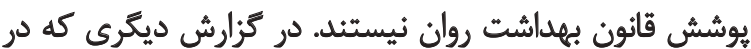

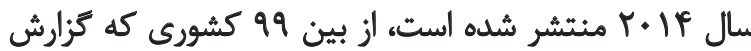

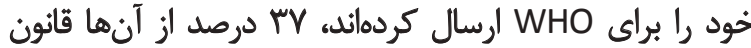

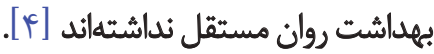


جدول ا. درصدكشورهايي كه در طول زمان قانون در زميئه بهداشت روان داشتهاند

\begin{tabular}{|c|c|}
\hline درصد كشورها & سالها \\
\hline $10 / 9$ & 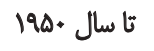 \\
\hline NV & $197 \cdot-1981$ \\
\hline 1.11 & $14 \cdot-197$ \\
\hline $\mid r / T^{\prime}$ & $199 .-1411$ \\
\hline $1 \cdot 18$ & $r \ldots-1991$ \\
\hline$I r / N$ & بعل از Y... \\
\hline
\end{tabular}

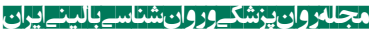

مستقلى براى بهداشت روان تاكنون مدون نشده است، از ديرباز در

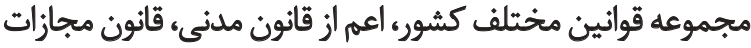

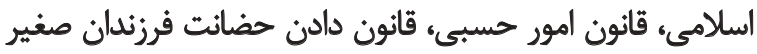

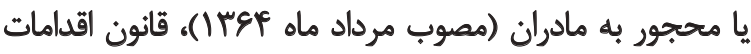

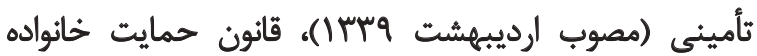

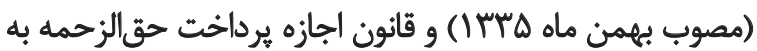

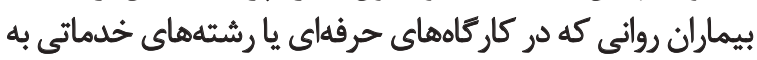

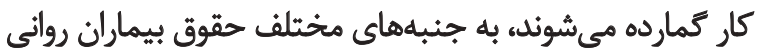

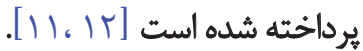

در اين قوانين از اصطلاحاتى همجيون جنون، سفيه، اختلال

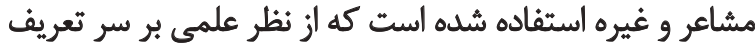

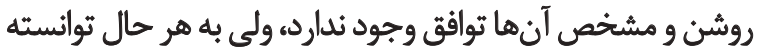

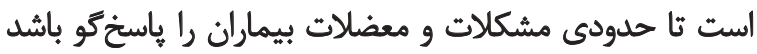

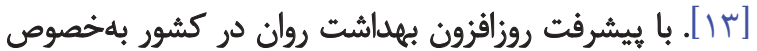

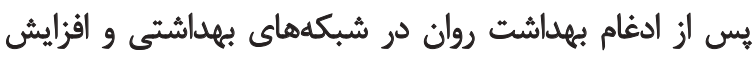

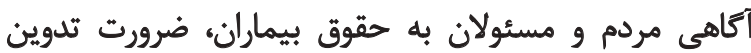

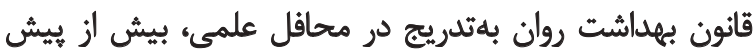

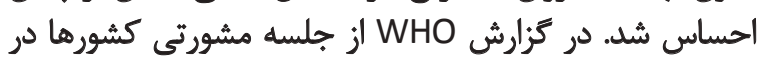

منقول است كه: الرسول كرامى (ص) در ميان اصحاب بود كه

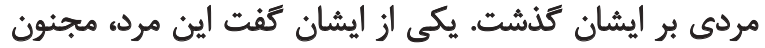

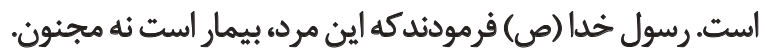

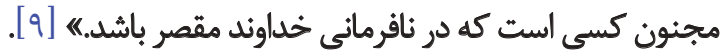
علاوه بر اين، رعايت احترام به حقوق بيماران در فقه اسلامى

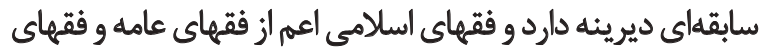

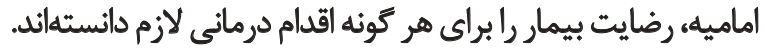

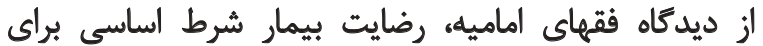

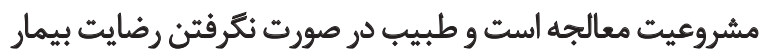

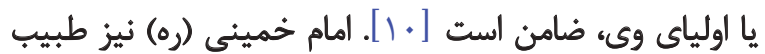

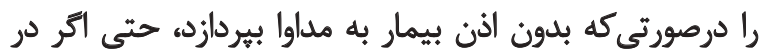

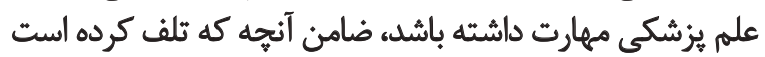

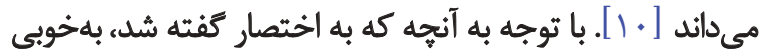

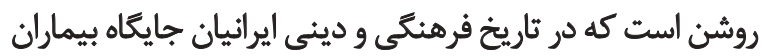

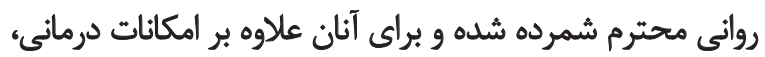
حقوقى نيز در نظر كرفته شده است. بررسى قوانين موجود در ايران نشان مى دهد كه اكرجه قانون

جدول r. وضع قوانين بهداشت روان در مثاطق مختلف سازمان بهداشت جهانى

\begin{tabular}{|c|c|c|}
\hline درصد جمعيت تحت بوشش & درصد كشورها & مناطق WHO \\
\hline $9 p / 4$ & Va/s & الفريقا \\
\hline งิ/ & va & امريكا \\
\hline$V \cdot / A$ & $\Delta V / 1$ & هديترائه شرقى \\
\hline 9.11 & $91 / 1$ & 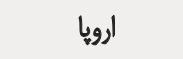 \\
\hline $9 \Delta / 9$ & $\varepsilon \pi / 8$ & جنوب شرقى آسيا \\
\hline $1 w / 9$ & ve & غرب اقيانوس آرام \\
\hline$s q / 1$ & ra & جهان \\
\hline
\end{tabular}




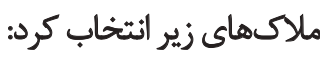

مشاركت افراد از مراكز دانشكاهي مختلف، تنوع تخصصى كروه

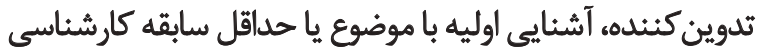

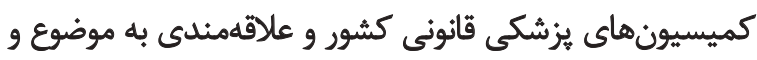

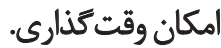
با رعايت ملاكهاي مذكور كروه اوليه با ينج روانيزشك عضو

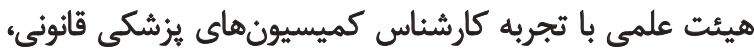

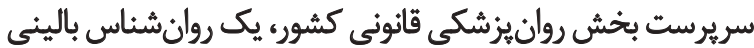

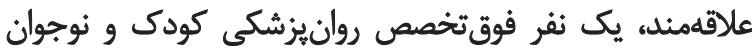

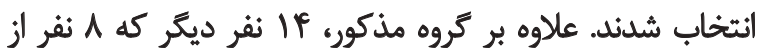

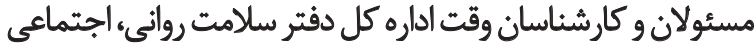

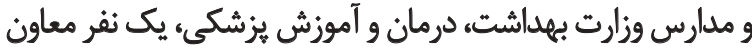

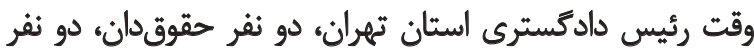

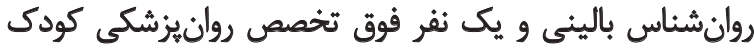

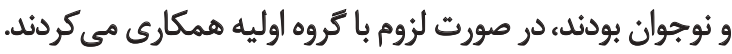

در جلسات اوليه بر سر روش كار به اين شرح توافق شد:

بررسى مقررات و قوائين بينالمللى در خصوص تدوين قانون؛

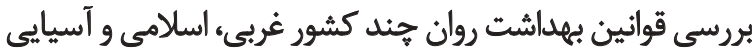

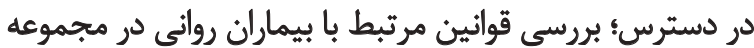

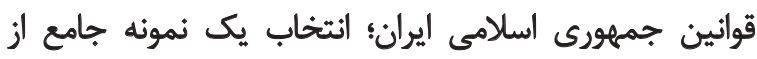

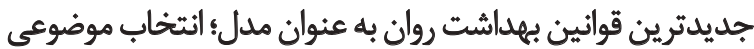

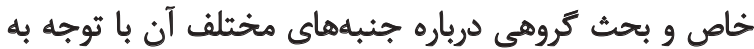

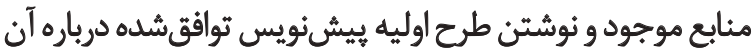

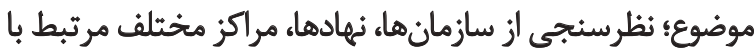

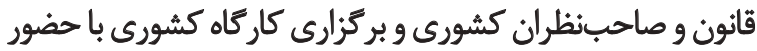

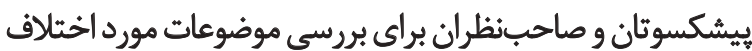
و نهايى كردن متن بيشنويس قانون اين مرحله حدود دو سال به طول انجاميد. طى اين دو

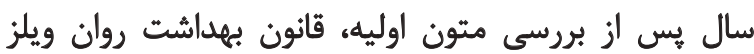

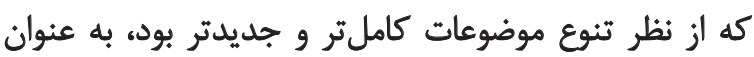

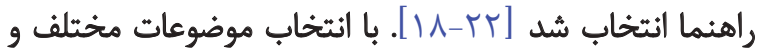

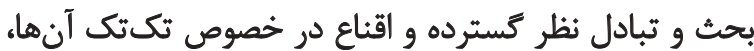

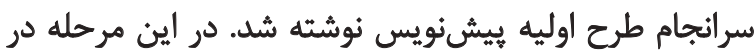

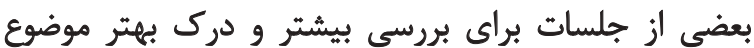

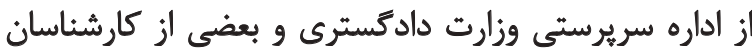

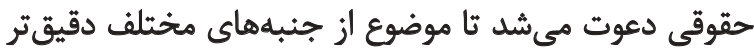
تجزيهوتحليل شود. در تيرماه

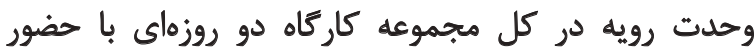

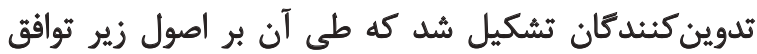

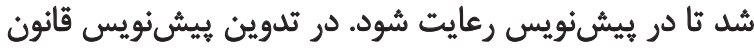

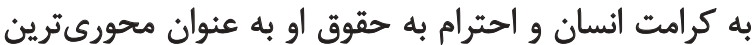

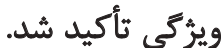

خصوص قانون بهداشت روان در كويت (1997)، مشاور ايرانى

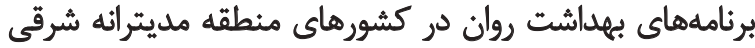

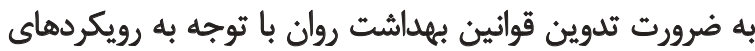

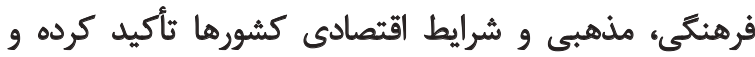

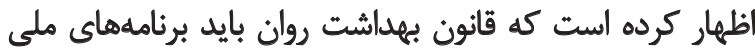

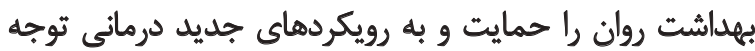

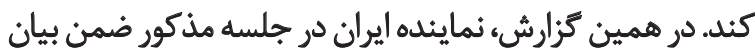

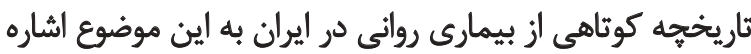

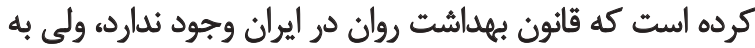

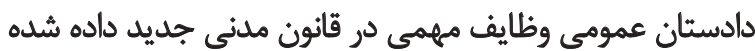

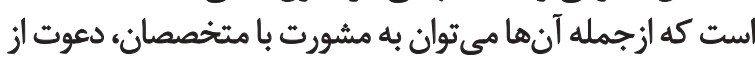

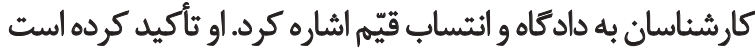

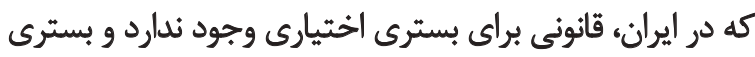

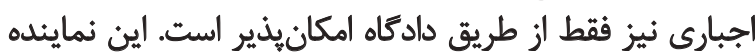

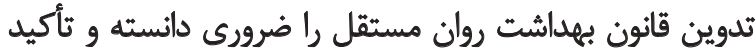

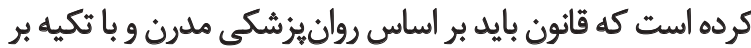

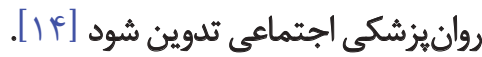

در سال IrVA نخستين فراخوان همكارى براي تهيه بيشنويس قانون بهداشت روان را در جمهورى اسلامى ايران

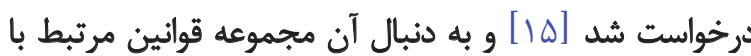

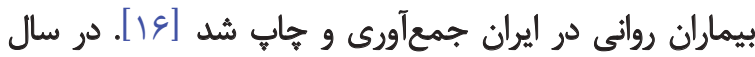

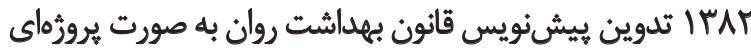

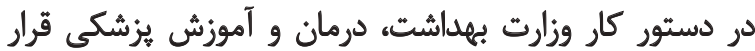

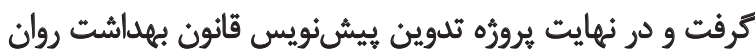

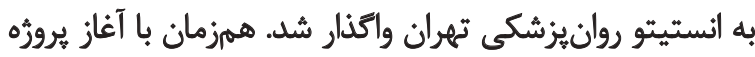

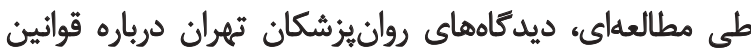

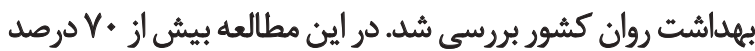

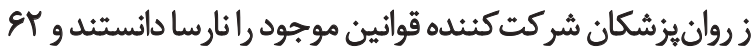

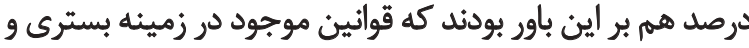
ترخيص بيماران نارساست [IV] ووشّ

ييشنويس قانون بهداشت روان در سه مرحله متفاوت تدوين

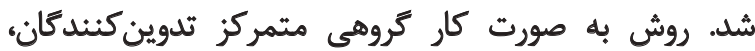

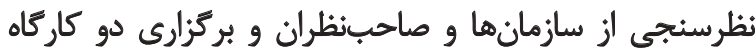
كوجى و دو كاركاه كشورى بودان

$$
\text { فرايثد ثدوين طرح يشيثويس قائون سلامث روان }
$$

مرحله اول: تدوين طرح اوليه

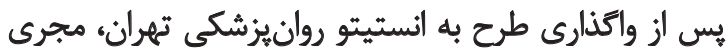

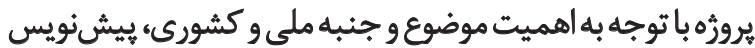

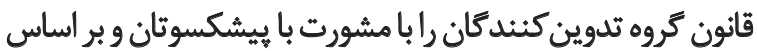




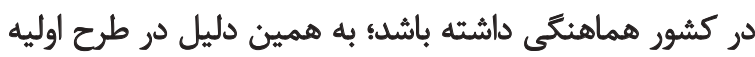

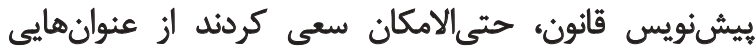

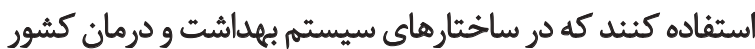

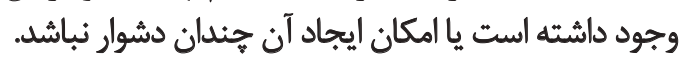

يس إز بركزارى كاركاه و تعيين خط مشى كلى، براى تحقق

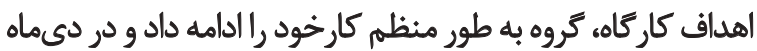

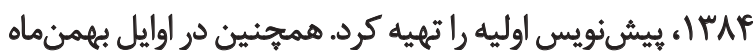

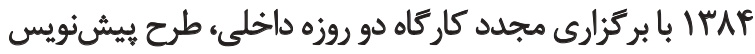

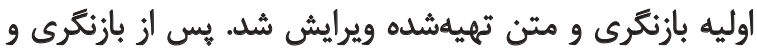

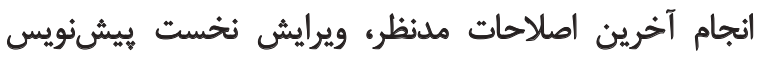

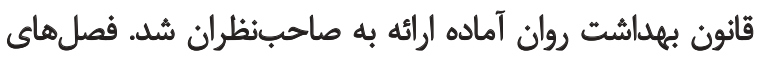

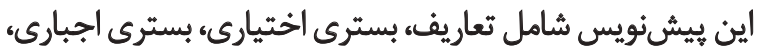

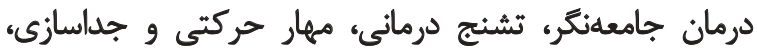

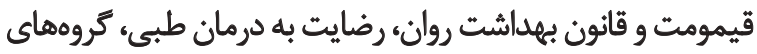

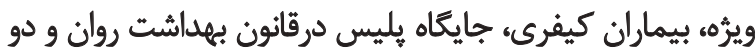

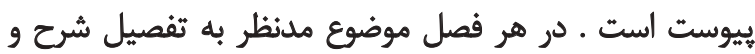

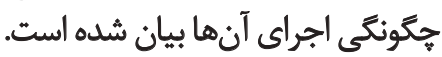

\section{كسب نظر كارشناسان و سازمانها}

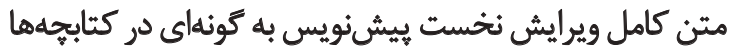

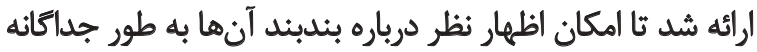

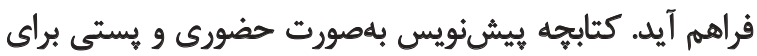

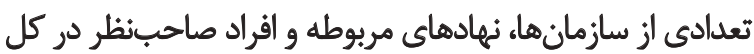

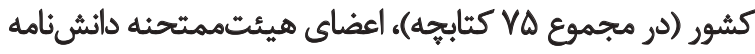

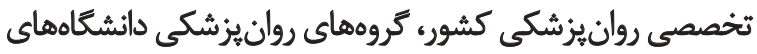

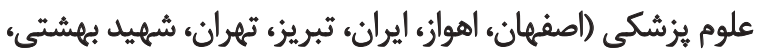

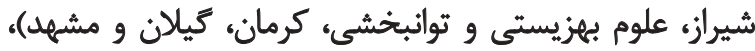

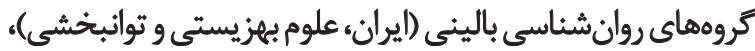

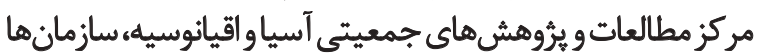

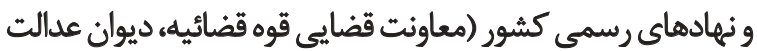

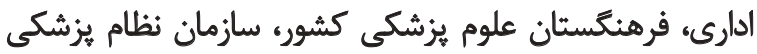

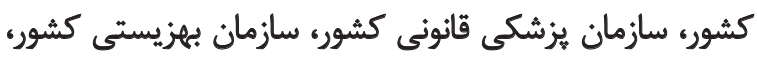

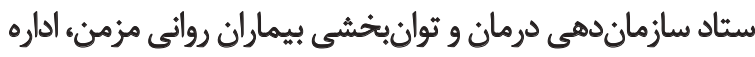

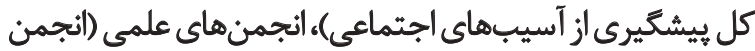

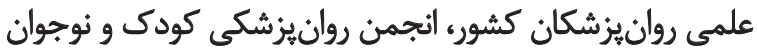

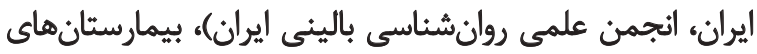

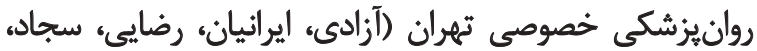

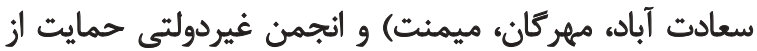
بيماران اسكيزوفرنيا (احبا) فرستاده شدان

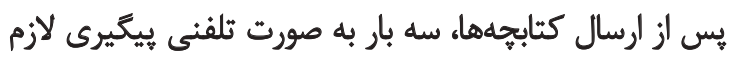

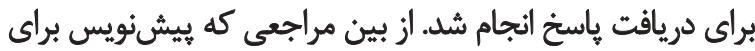

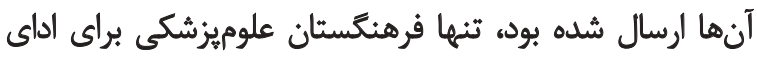

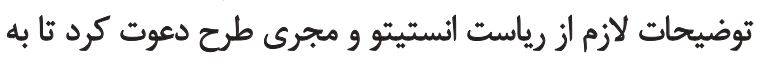

\section{انتُحاب وارَّان جديد}

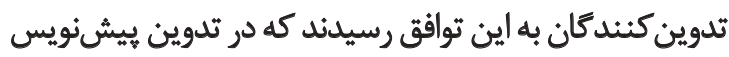

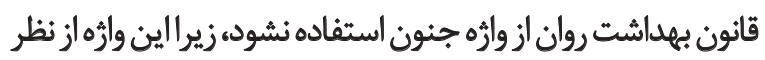

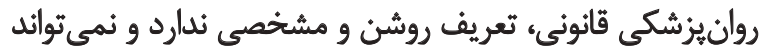

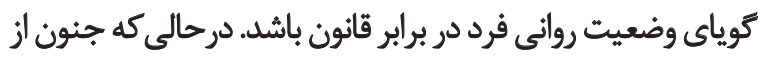

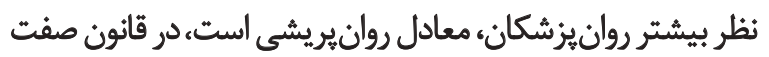
كسى است كه قدرت تشخيص نفع و ضرر و حسن حسن و قبح ران راندارد

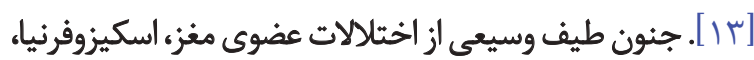

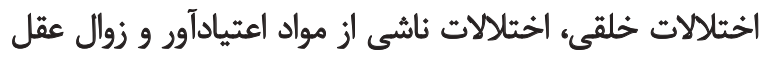

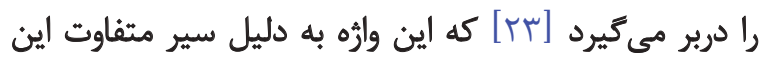
اختلالات، نمي تواند كوياى وضعيت رواني إنى فرد در برابر قانون باشيد. به عبارت ديكر، فرد روانيريش ميثتواند عملكرد خوب و فرد

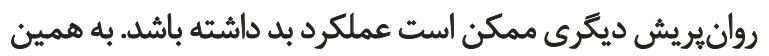

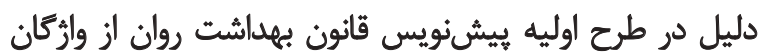

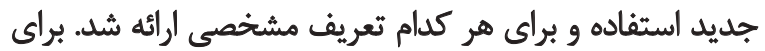

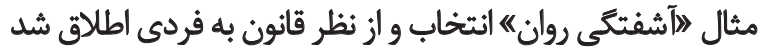

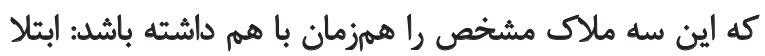

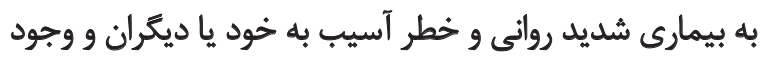

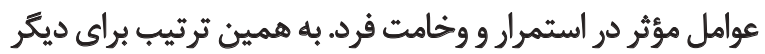

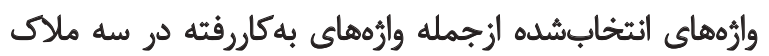
مذكور نيز تعريف مشخصى ارائه شد. والثكان اصلى كه مقرر شد در طرح اوليه به كار كرفته شونده عبارت

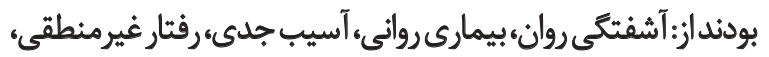

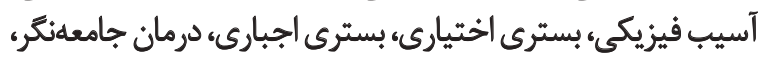
مهار حركتى، جداسازسى، بيماران كيفرى و رضايت.

\section{انطباق ييشنويس با قوانين موجود}

تدوين كنئدكان ثلاش كردند ثا با بهرهگيرى از قوانين جارى

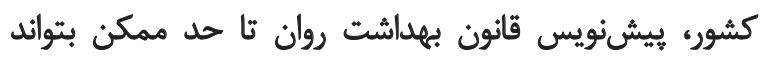

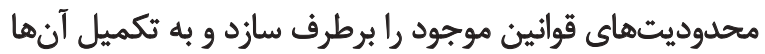

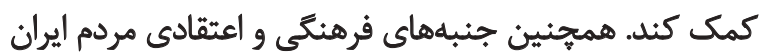
در آن لحاظ شود.

\section{بهرهتيرى از تعاليم اسلامى}

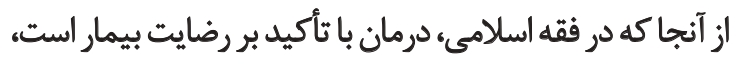

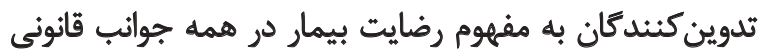

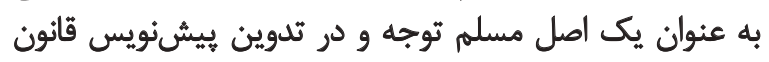
بهداشت روان بر آن تمركز ويره كردند.

$$
\text { قابليت اجرا }
$$

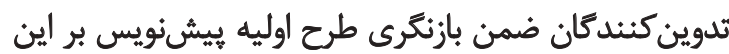

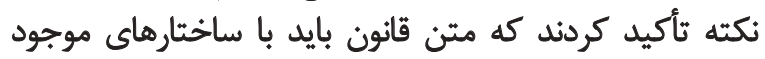


بسترى اجبارى (ع اعورد) و كمترين آنها درباره يويوست شماره ب بود (1ل المورد).

تدوين كنيدكان طى جهندين جلسه تكتئك نظرات استادان،

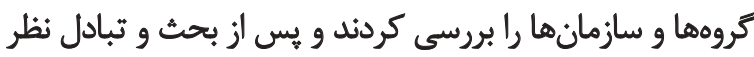

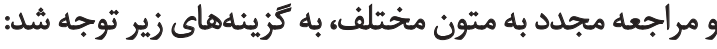
•بعضى از نظرات بيشنهادى يذيرفته شد و در متن بيشنون إيشيس

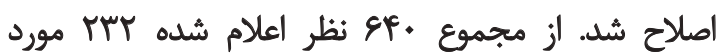

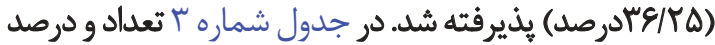

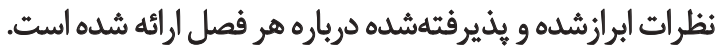
•بعضى از ي يشنهادهاى ارائهشده با وجود جالب توجه بودن، در براد

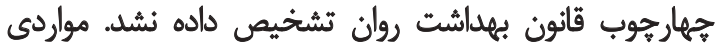

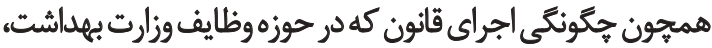

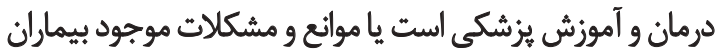

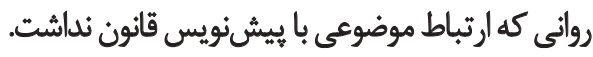

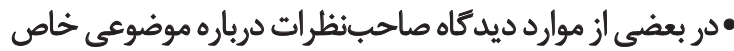

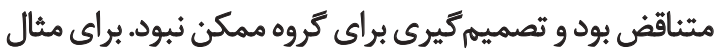

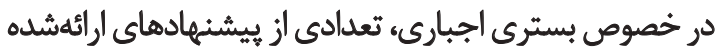

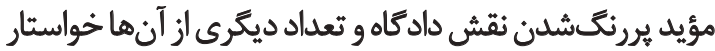

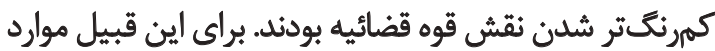

صورت حضورى در جلسه آنان حاضر شوند. به دنبال اين درخواست

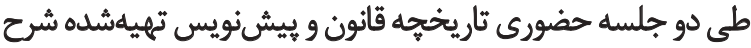

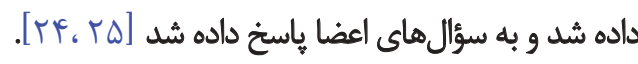

يافتهها

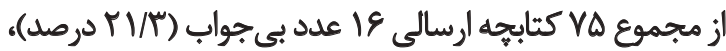

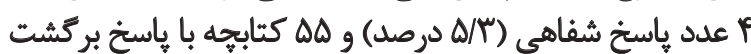

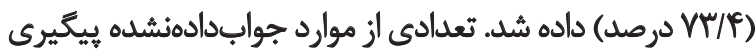

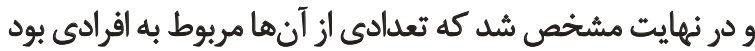

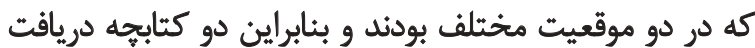

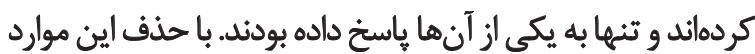

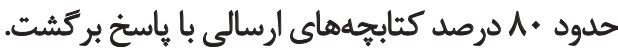

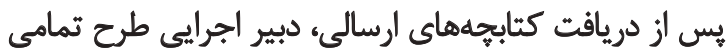

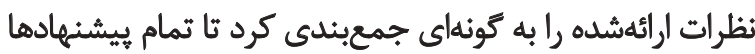

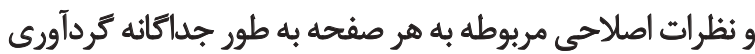

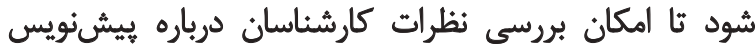

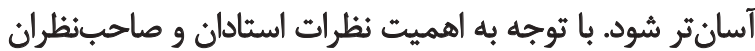

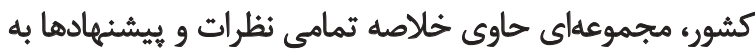

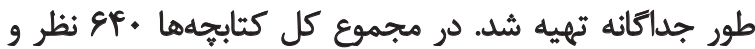

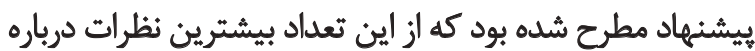

جدول ب. تعلداد نظرات ابرازشده همراه با تعداد و درصد نظرات بذيرفتهشده در هر فصل

\begin{tabular}{|c|c|c|}
\hline تعداد و درصد نظرات بذيرفته شده & تعداد نظرات ارائه شده & نام فصل \\
\hline$r \Lambda(\mu \circ M)$ & 91 & تعاريف \\
\hline $19(\Delta) / T)$ & $r$ & بسترى اختيارى \\
\hline$\varepsilon \cdot(m V)$ & Iar & بسترى اجبارى \\
\hline$r \Delta(r T / M)$ & qf & درمان جامعهنكر \\
\hline 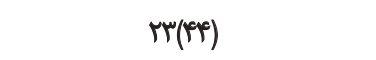 & $\Delta$. & تشنجندرمائي \\
\hline$M(r q / 1)$ & te & مهار حركتى و جداسازى \\
\hline$V(r \Delta)$ & rA & قيمومت و قانون بهدائشت روان \\
\hline$q(T \omega / T)$ & iv & رضايت به درمان طبى \\
\hline IV(re/q) & te & كروههاى ويثره \\
\hline$r(1 Q)$ & r. & بيماران كيفرى \\
\hline$A(r e / M)$ & M & جايكاه هيليس در ثائون بهباثت روان \\
\hline$\Delta\left(T^{N} / T\right)$ & 18 & ييوست | \\
\hline$P($ PE/T) & 11 & بيوست Y \\
\hline THr/(rg/TQ) & ge. & جمع \\
\hline
\end{tabular}


جدول f. موضوعها و سؤال هاي مطرحشده در كار كاه كشورى مشكيندشت كرج

\begin{tabular}{|c|c|c|}
\hline سؤالهاى مطرحشده & عنوان موضوع & رديف \\
\hline 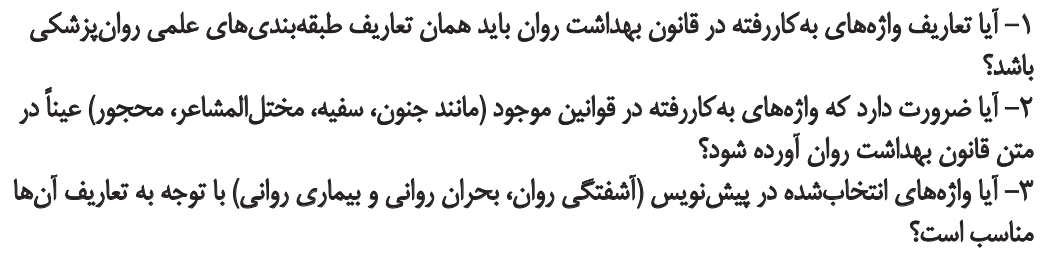 & والزهها & 1 \\
\hline 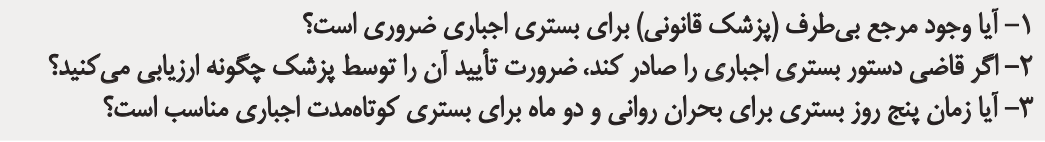 & بسترى اجبارى & $r$ \\
\hline 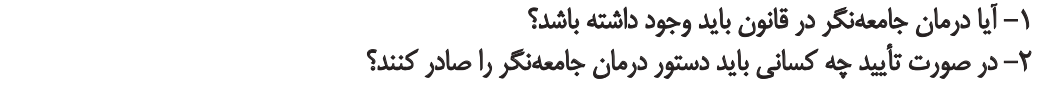 & درمان جامعلنكر & $r$ \\
\hline 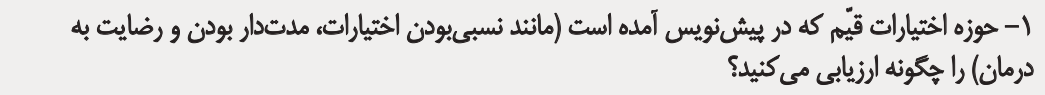 & قيموهت & $f^{f}$ \\
\hline
\end{tabular}

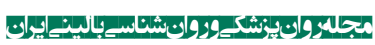

يس از بهايان كاركاه كشورى، تدوين كنئدكان طى جلى جلسهاي

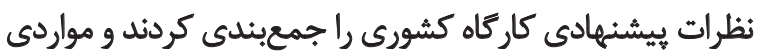

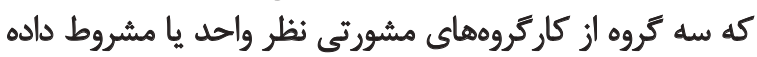

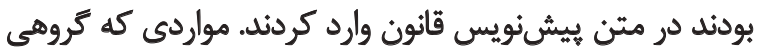

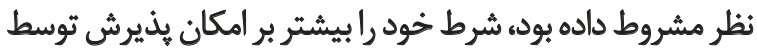

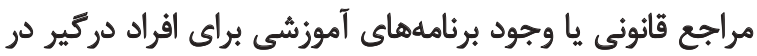

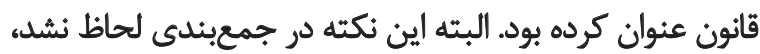

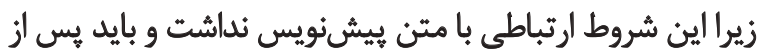

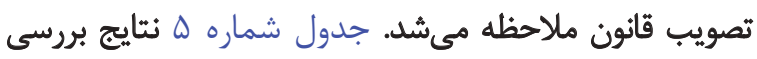

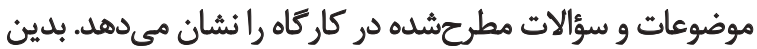
ترتيب ويرايش سوم بيشنويس آماده شد.

مرحله دوم: ثبديل ييش نويس بك مواد ثانونى

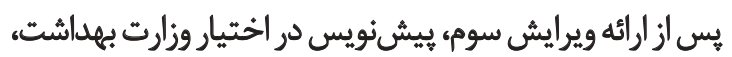

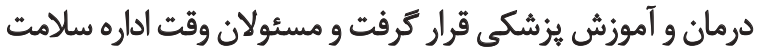

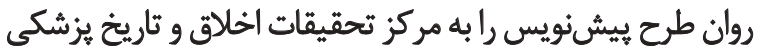

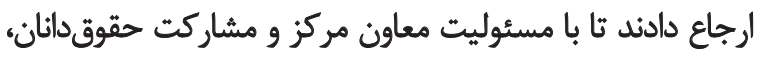

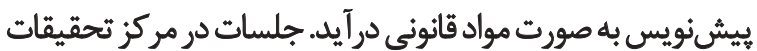

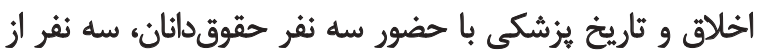

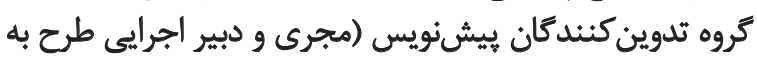

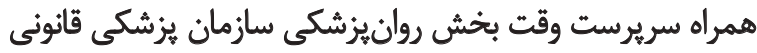

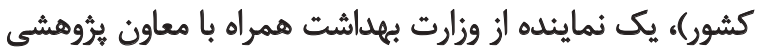

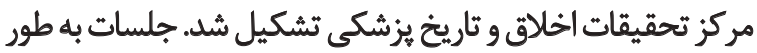

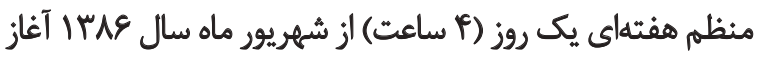

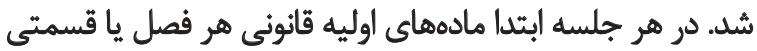

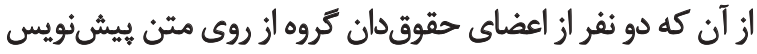

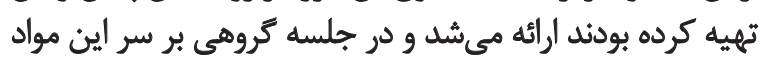

كروه تصميم كيرى را بر عهلده صاحب نظران شركت كنينده در

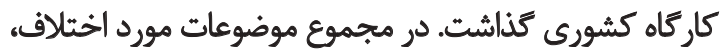

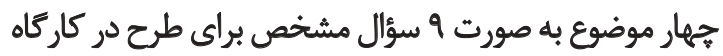

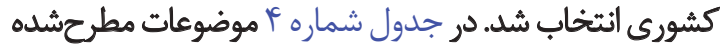
در كارگًاه كشورى همراه با 9 سؤال ارائه شده است.

بدين ترتيب يس از اعمال نظرات اصلاحي، ويرايش دوم

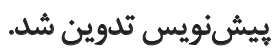

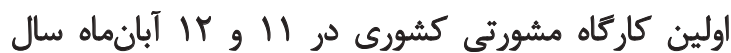

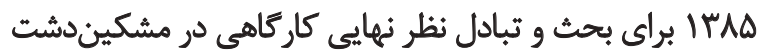

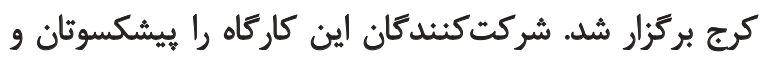

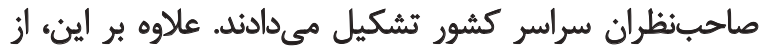

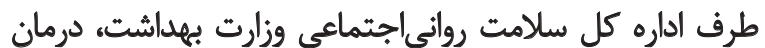

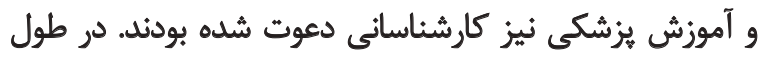

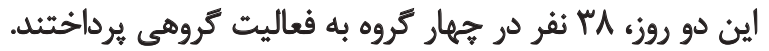

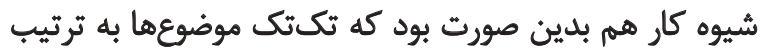

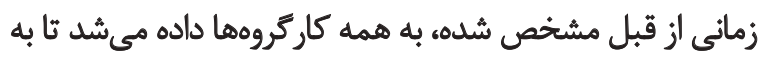

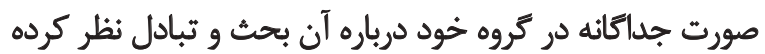

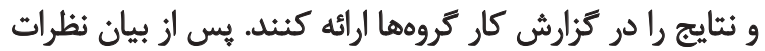

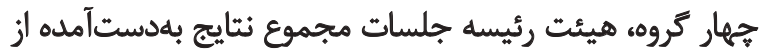

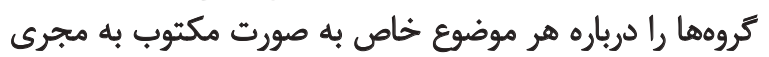

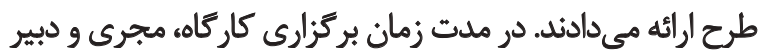

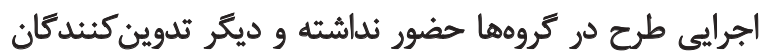

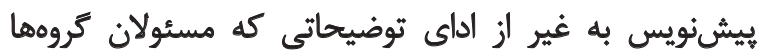

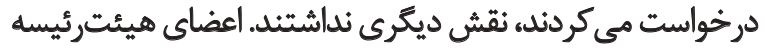

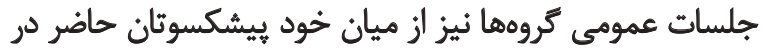
كاركاه انتخاب شله بودند. 


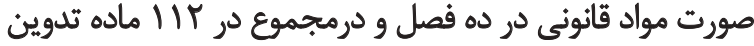

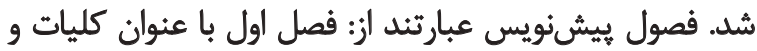

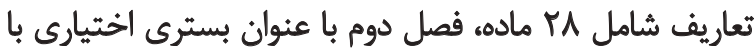

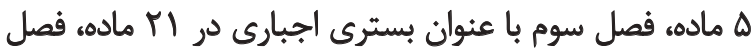

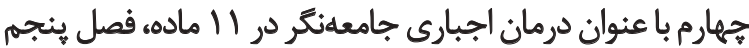

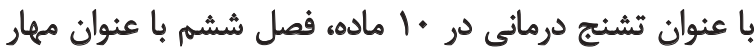

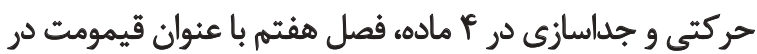

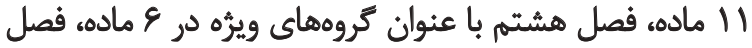

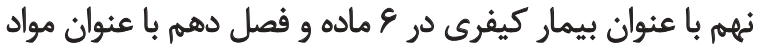

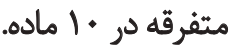

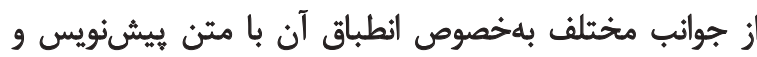

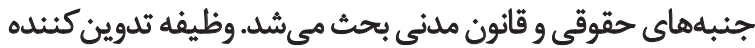

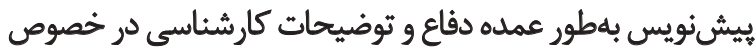

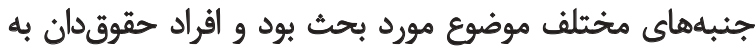

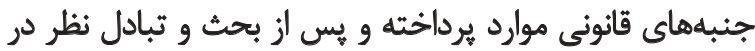

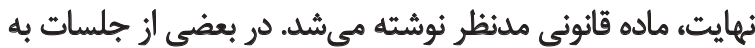

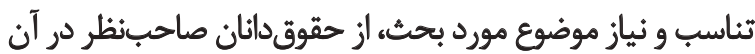

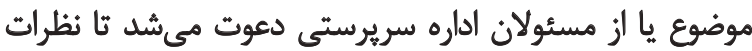
كارشناسى خود رادر آن زمينه خاص ارائه كنيند. سرانجام پپ از FV جلسه جهارساعته، بيشنويس قانون به

جدول ه. نتايج بررسى موضوعها و سؤالهاى مطرحشده در كاركروهاى كاركّاه كشورى مشكيندشت كرج

\begin{tabular}{|c|c|c|c|c|c|}
\hline كارتروه f & كارئروه r & كا, كروهه & كارئروه | & سوال & موضوع \\
\hline مخالف & مخخالف مشروط & مخالف & مخالف & 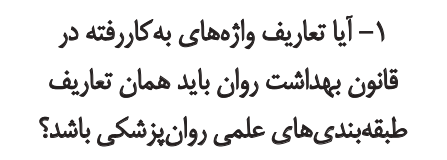 & \\
\hline هخالف & مخالف & مخالف مشروط & مخالف & 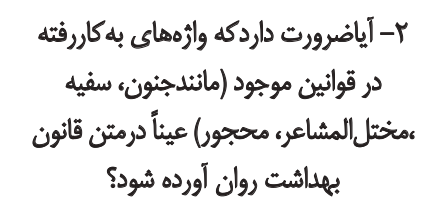 & وارثهـا \\
\hline موافق & موافق & موافق مشروط & بي بنظر & 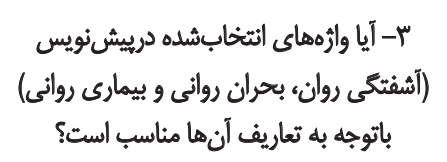 & \\
\hline موافق & موافق & موافق & موافق & 1- آيا وجود مرجع بى طرف (يزرشى قانونى) & \\
\hline ضروي است & ضرورى است & ضرورى نيست & ضرورى است & 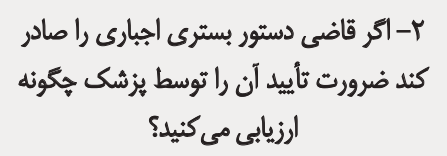 & اجبارى بـت \\
\hline ه روز و r ماه & Vوز وب ماه & ه روز و r ماه & ه روز و r ماه & 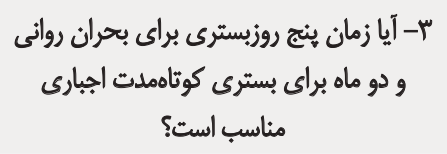 & \\
\hline موافق & هواقق & بدون نظر & مواقق & 1- آيا درمان جامعهنكر در قائون بايد وجود & دومان \\
\hline كميسيون يزشكي يا & 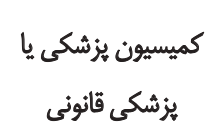 & ارجع با سيستم & كميسيون يز شكى روانيز شيك معتمد & ب-رو صورت تأييد جه كسانى بايد دستور & \\
\hline همبتب & مثبت & مثبت & مثبت & 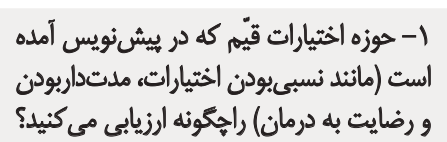 & قيمومت \\
\hline
\end{tabular}




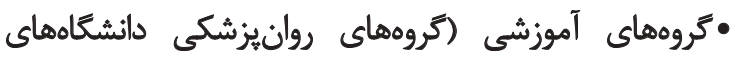

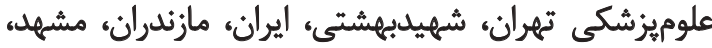

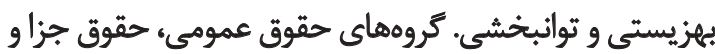

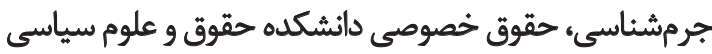

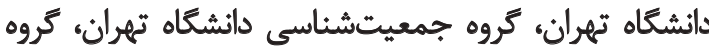

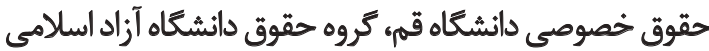
واحدهاى تهران شمال و مركزي)

•بيمارستان هاى روانيزشكى خصوصى تهران (آزادى، رضاعى،

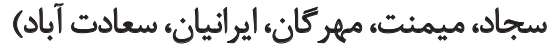
•انجمن هاى غيردولتي (انجمن حمايت از بيمار ان اسكيزوفرئيا،

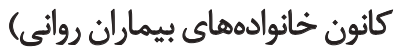

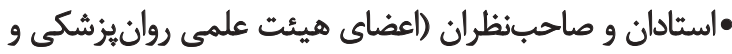

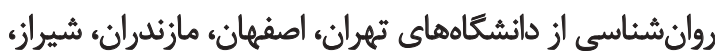

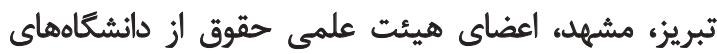

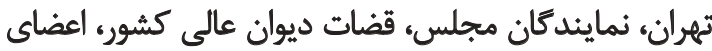

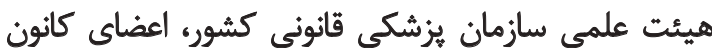
وكلا، اعضاى هيئت علمى مراكز تحقيقاتى ينى

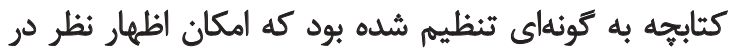

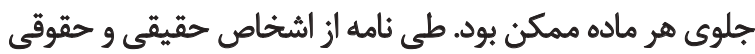

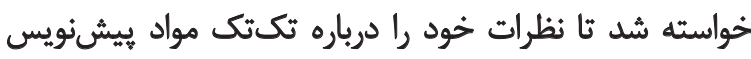

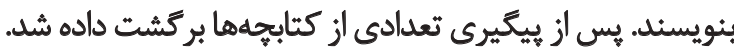

\section{تثايج نظرسنجى}

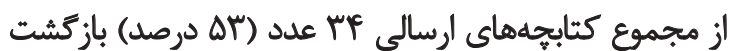

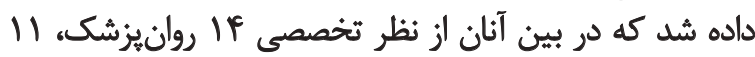

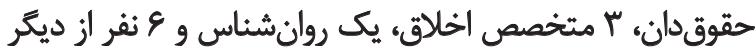

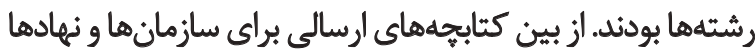

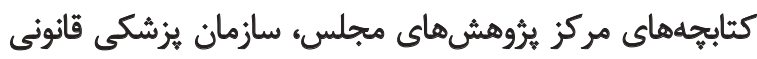

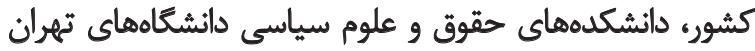

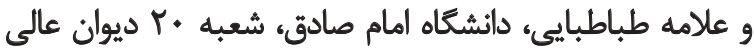

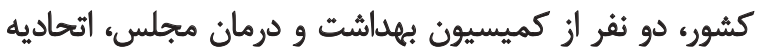
كانونهاى وكلا، كانون وكلاى دادئسترى، مركز

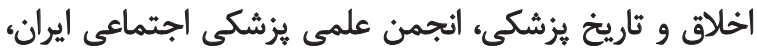

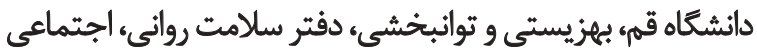

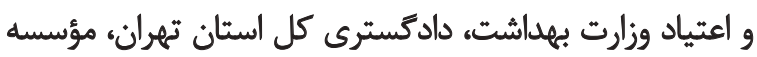

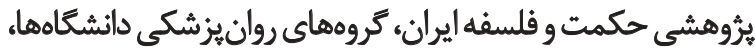

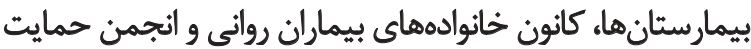

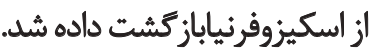

تمامى نظرات جمعآورى شده بهدقت در جلسات كروه بروسيى

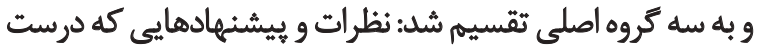

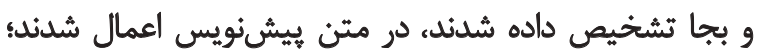

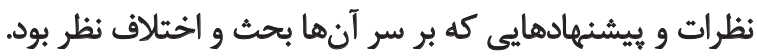

\section{كسب نظر كارشناسان و سازمانها}

متن بيشنويس تهيهشده بعد از تأييد تمامى همكاران تكثير

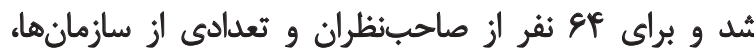
دانشكدهها، مؤسسات و نهادهاي مربوطه به شرح زير ارسال شد: •مجمع تشخيص مصلحت نظام (كميسيون حقوقى و قضايى نظماني

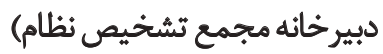

•قوه قضائيه (معاونت حقوق قوه قضائيه، معاونت آموزش قوه

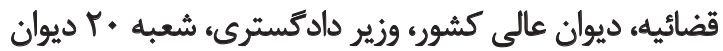
عالى كشور، دادستان عمومى و انقلاب تهران، اداره كل تلثئ تنقيح

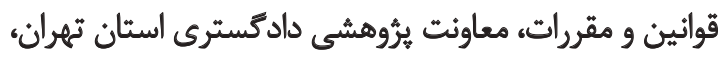

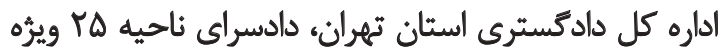

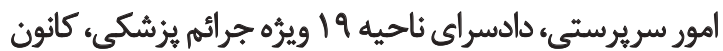
وكلاي دادكسترى، اتحاديه كانون وكلاح

•مجلس شوراى اسلامى (كميسيون بهداشت و درمان،

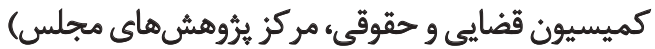
•وزارت بهداشت، درمان و آموزش بزشكى (معاونت سلامت،

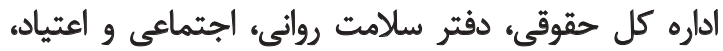

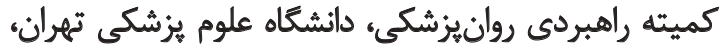
انستيتوى روانيزشكى تهران)

•وزارت علوم و تحقيقات (اداره كل حقوقى وزارت علوم، دانشكده

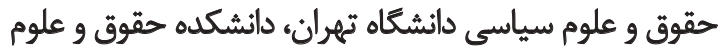

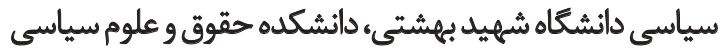

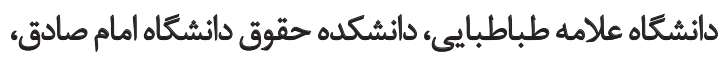

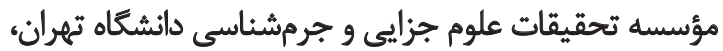

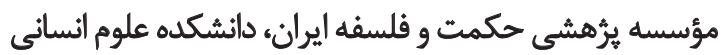
دانشكاه آزاد شهريار)

•انجمنهاى علمى (انجمن علمى روانيزشكان ايران، انجمن

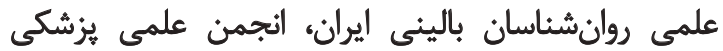

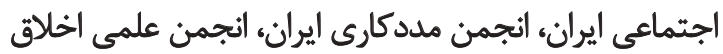

$$
\text { در علوم فناورى) إنمان }
$$

•مراكز تحقيقاتى (مركز تحقيقات روانيزشكى دانشَاه علوم

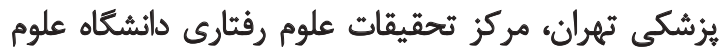

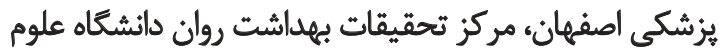

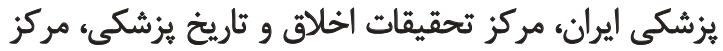

$$
\text { تحقيقات اخلاق و حقوق يزشكى إنى }
$$

•نيروى انتظامى (فرمانده نيروى انتظامى، يليس خيشكَيرى

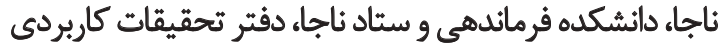

$$
\begin{aligned}
& \text { بليس بيشكيرى ناجا) } \\
& \text { •سازمان بزشكى قانونى كشور }
\end{aligned}
$$


مرحله سوم: خاصلاصكودن بيشنويس

بس از ارائه ويرايش جهارم به وزارت بهداشت، درمان و

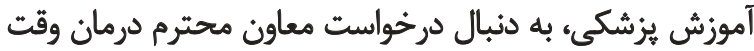

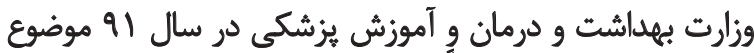

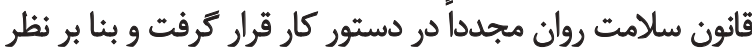

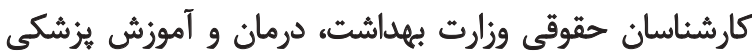

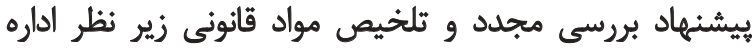

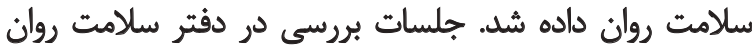

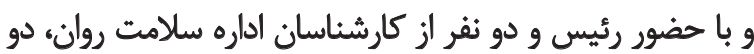

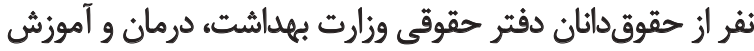

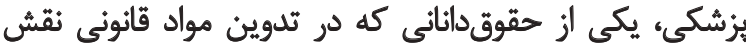

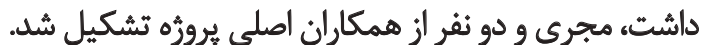
جلسات هفتهاى يكبار تشكيل و حدود جهار ساعت طول

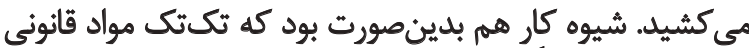

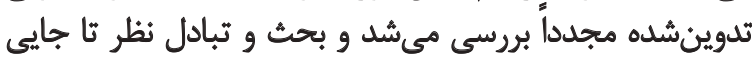

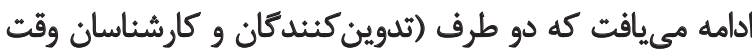

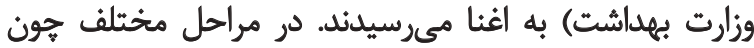

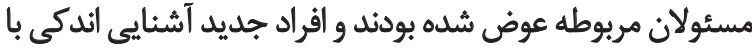

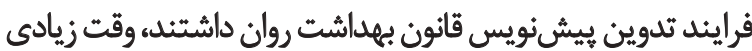

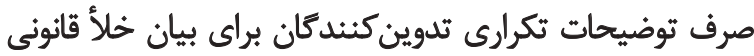

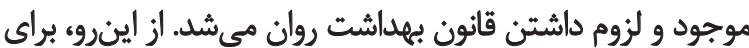

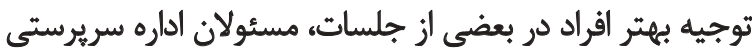

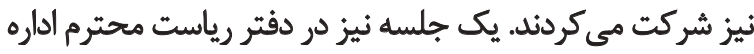

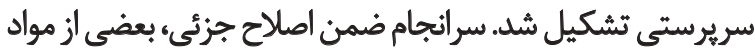

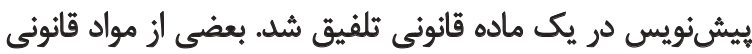

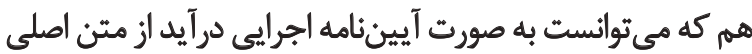

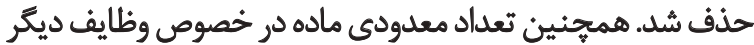
سازمانها درباره ثانون سلامت روان تدوين و به آن افزوده شد.

بحث

سرانجام يس از 9 سال، بيشئويس قانون با يك ماده به عنوان

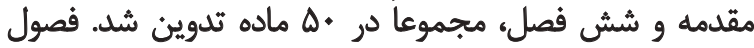

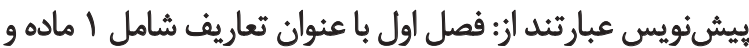

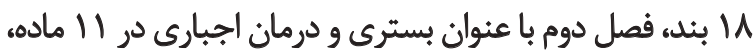

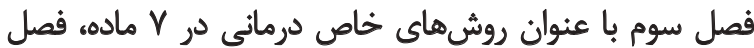

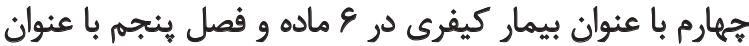

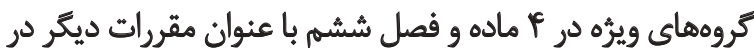

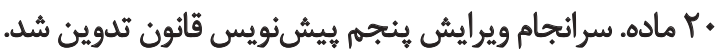
در فصل اول تمامي والرههاى بهكاررفته در بييشنويس قانون

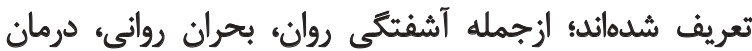

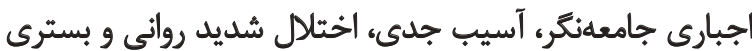

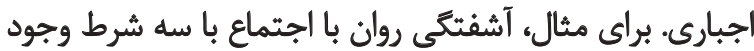

اين موارد عبارت بودند از: شرايط بسترى و درمان اجبارى، نسبى تيمي

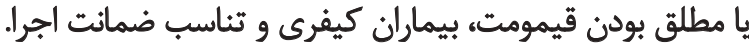

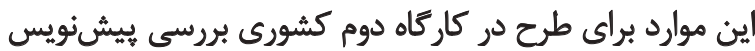

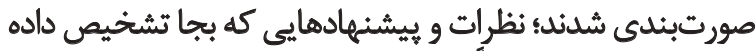

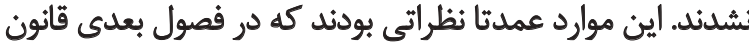

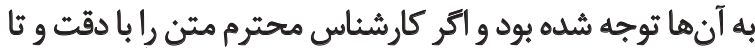

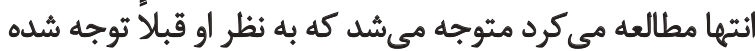

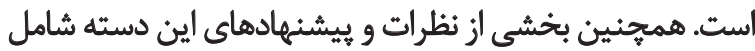

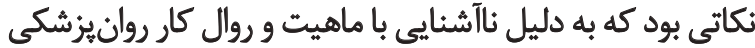

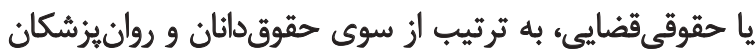

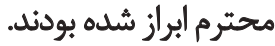

براى مثال، برخى از حقوقدانان هرگّونه محدودكردن

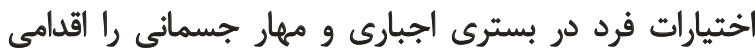

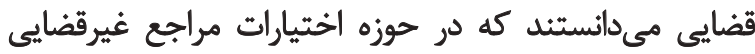

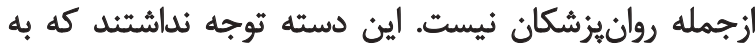

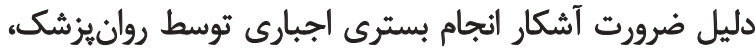

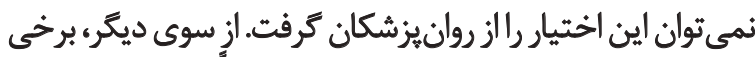

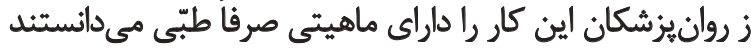

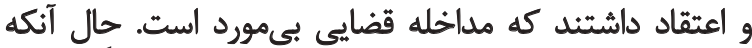

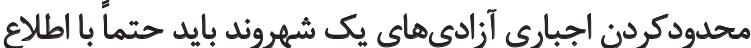
و تأييد صريح يا ضمنى مقام قضايى انجام كيردي

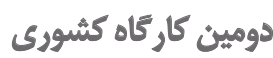

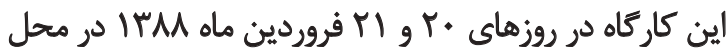

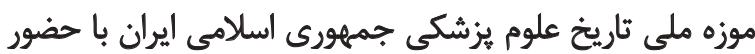

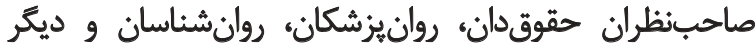

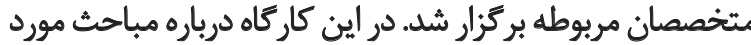

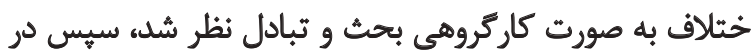

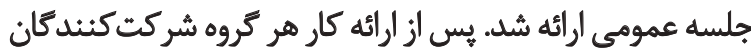

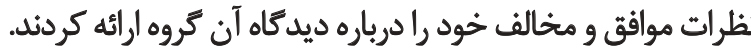

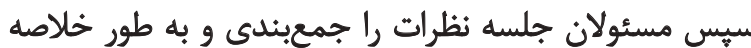
نتيجه آن را به مجرى طرح اعلام كردند.

در قايان كاركاه، جمعبندى نشست عمومى در اختيار

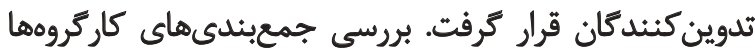

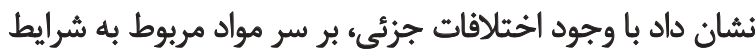

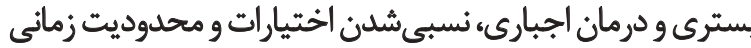

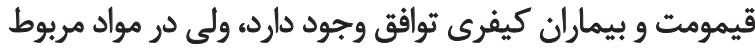

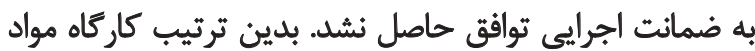

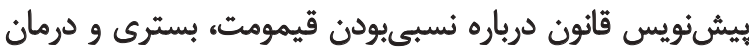

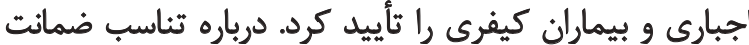

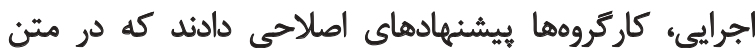

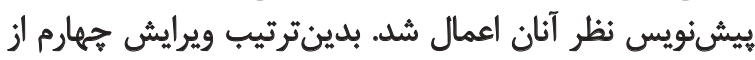

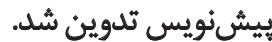


مرحله نظرسنجى وسيع از صاحبنظران و بركزارى دو كاركاه

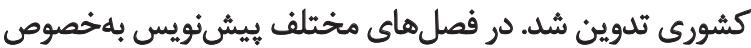

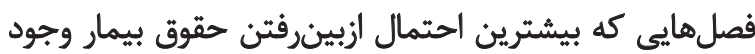

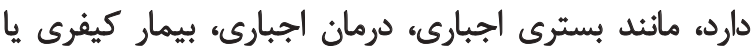

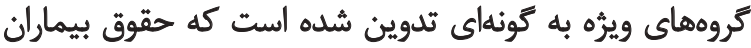

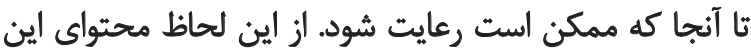

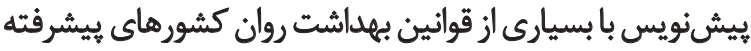

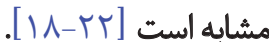

از آنجا كه در ايران مبانى فقهى نقشى اساسى در تدوين قوانين

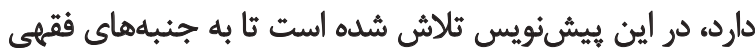

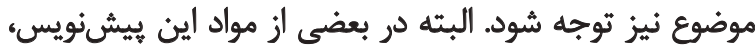

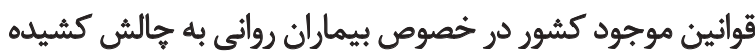

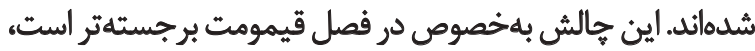

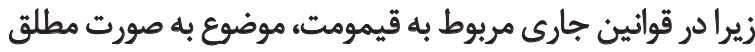

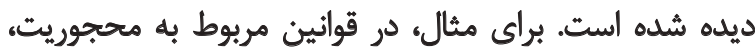

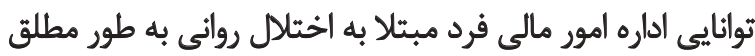

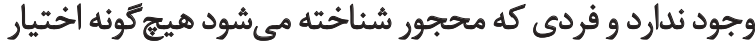

در زمينه امور مالى خود ندارد [1 11 ].

در اين بيشنويس بحث بر سر نسبىبودن اختيارات و

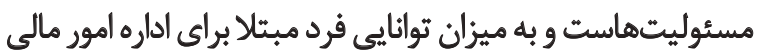

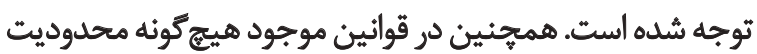

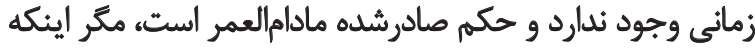

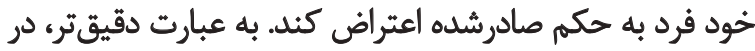

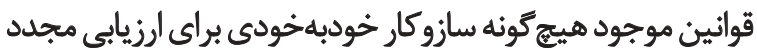

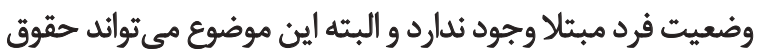

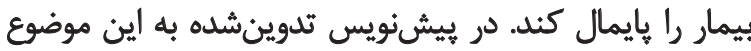

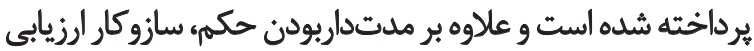

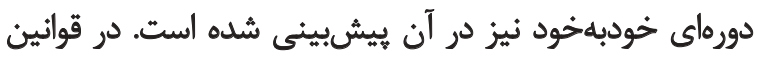

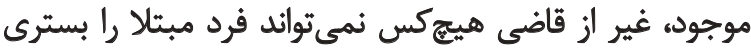

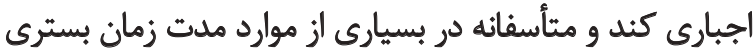

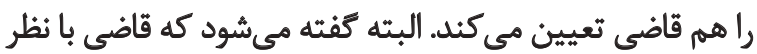

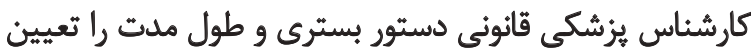

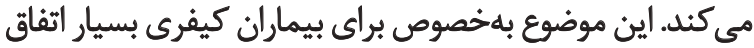

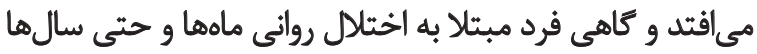

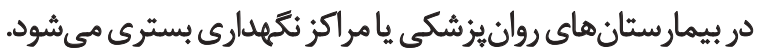
در صورت امتناع مركز از اجراى دستور دادستان، بزشك به

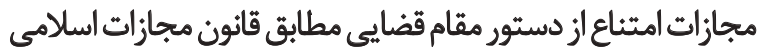

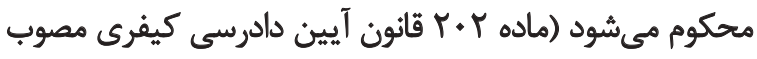

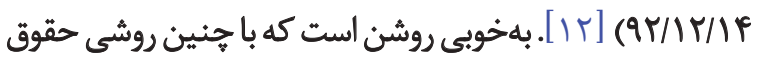

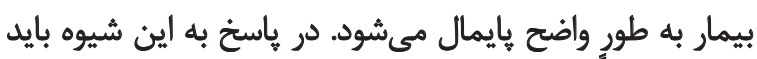

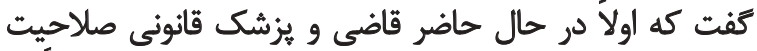
علمى تصميمكيرى درباره اين قبيل بيماران راض راندارد و ثانياً دران
اختلال شديد روانى و خطر آسيب جدى به خود يا ديكران و

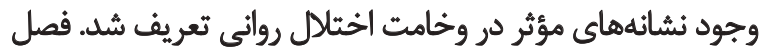

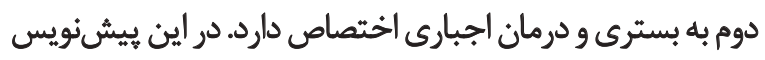

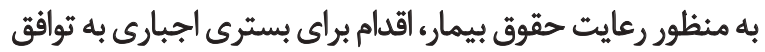

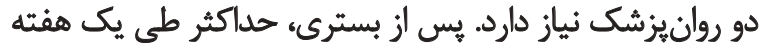

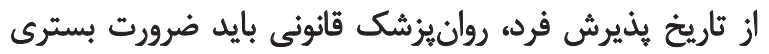

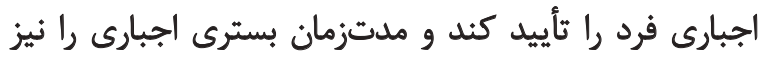

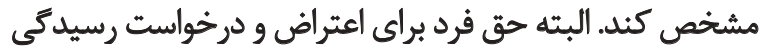
لحاظ و راهكارهاى قانونى بيشبين فرد ينى شده است. فصل سوم به روشهاى خاص درمانى اختصاص دارد. در در

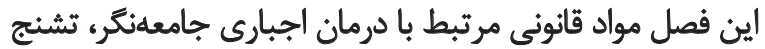

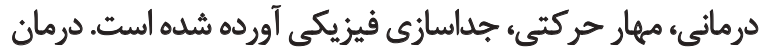

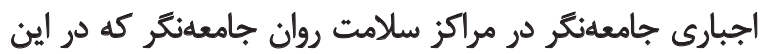

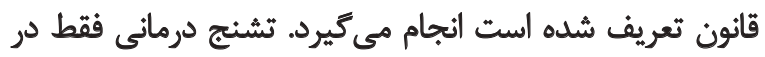

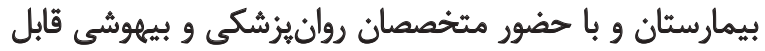

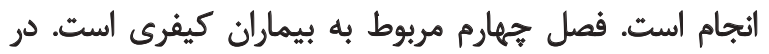

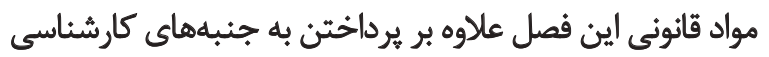

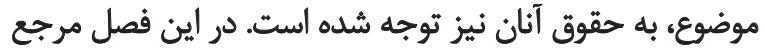

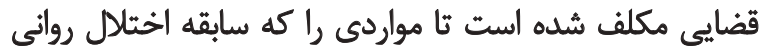

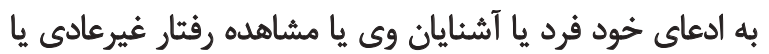

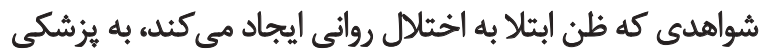

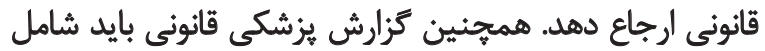

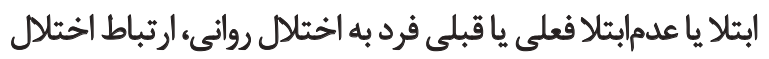

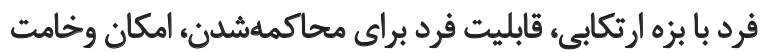

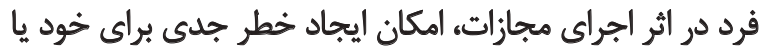

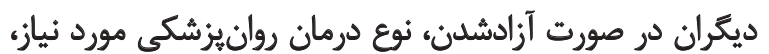
لزوم يا عدملزوم بسترى اجبارى باشد.

فصل ينجم درباره گروههاى ويزٔه است. بر اساس اين قانون

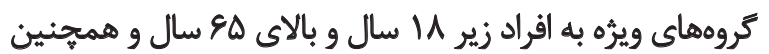

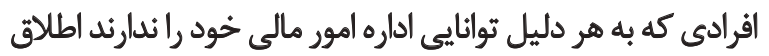

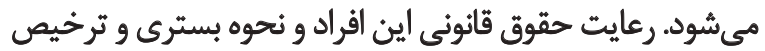

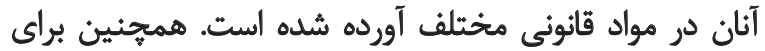

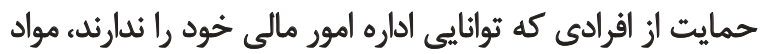

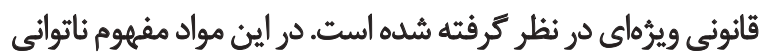

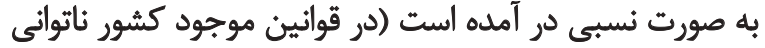

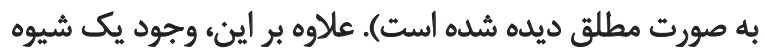

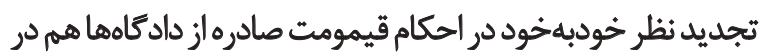

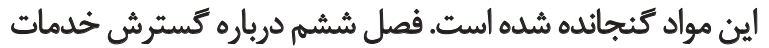

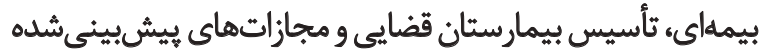

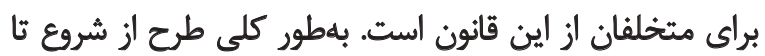

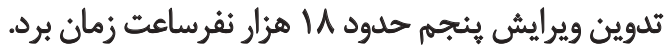
يّيشنويس قانون بهداشت روان سرانجام يس ازئ كار فشرده

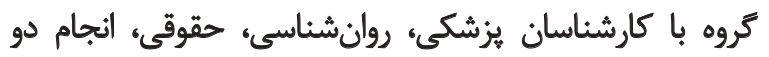


اجرايي كردن آن است.

بنابراين، تدوينكندكان آرمانگرايى نكردهاند و تثلاش

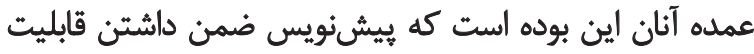

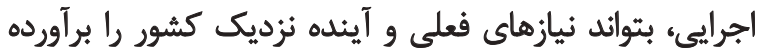

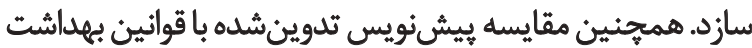

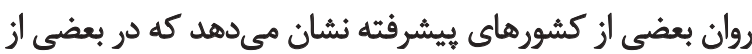

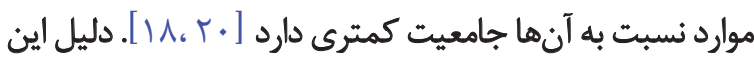
موضوع هم اين است كه بسيارى از ساختارهايى كه درد در سيستم

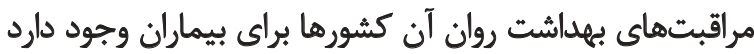

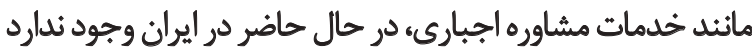

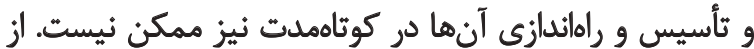
اينرو، اين موارد در بيشنويس آورده نشده است. در تدوين بيشنويس قانون سلامت روان تلاش كستردماى

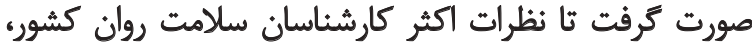

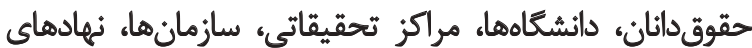

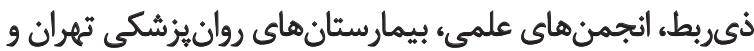

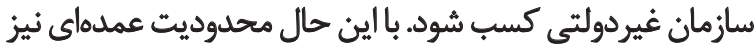

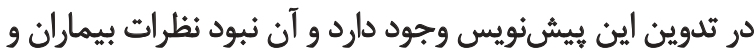

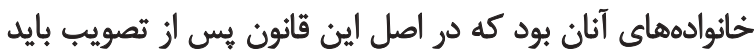

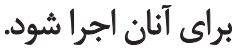

\section{نتيجليَيرى}

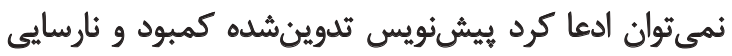

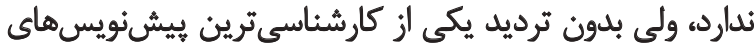

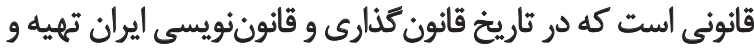

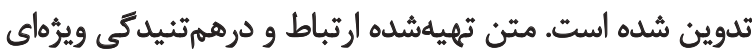

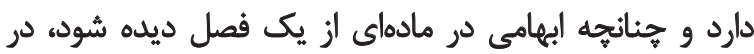

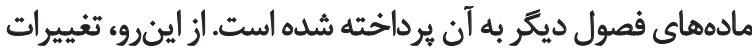

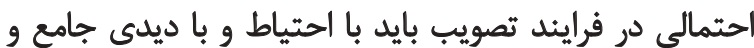

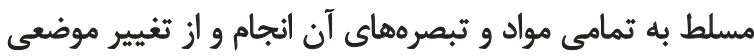

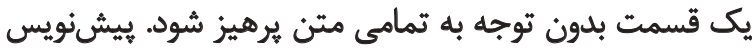

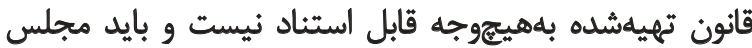
شوراى اسلامى آن را تصويب كند.

\section{سباستًّرَارى}

اين يرورةه با حمايت مالى دفتر سلامت رواني، اجتماعي و اعتياد

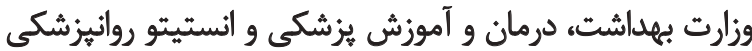

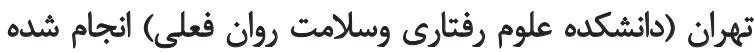

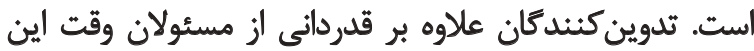

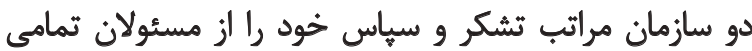

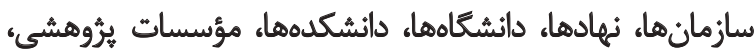

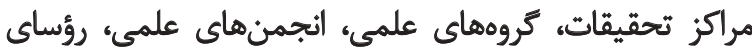

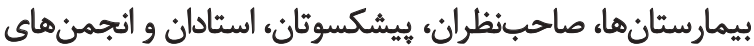

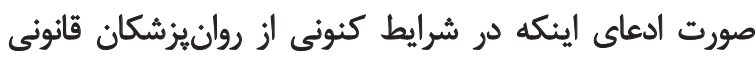

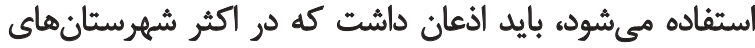

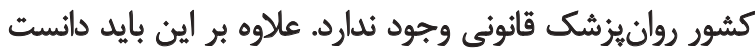

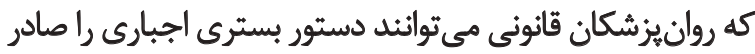

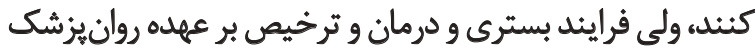

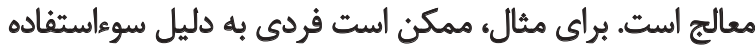

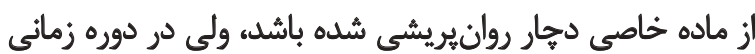

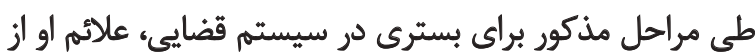

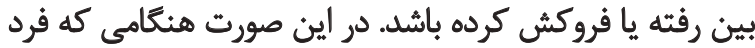

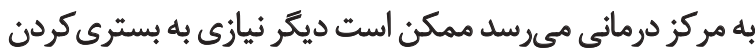

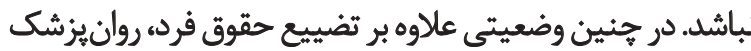

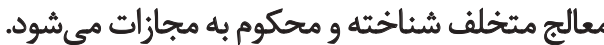
افرادى كه به بيمارى رواتى مبتلا هستند ولى كيفرى نيستند،

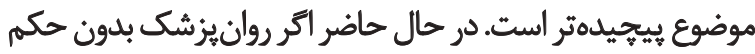

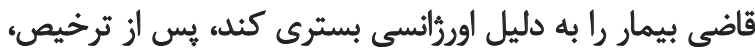

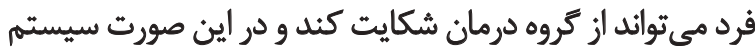

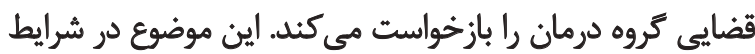

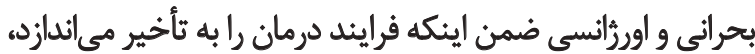

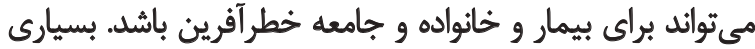

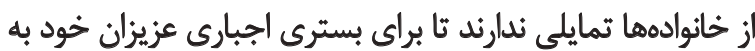

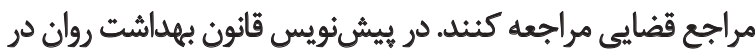

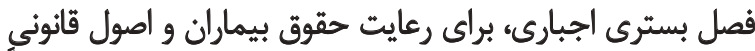

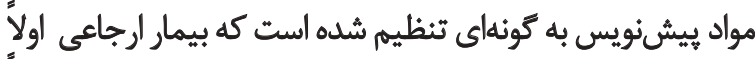

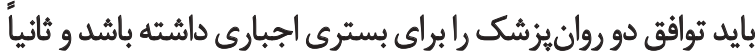

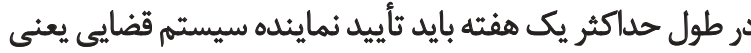

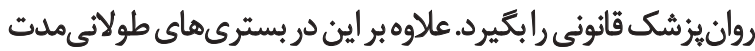

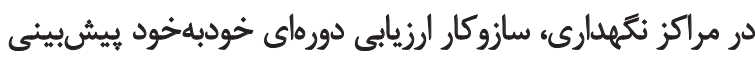

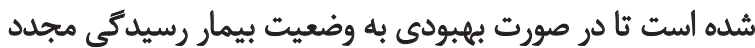

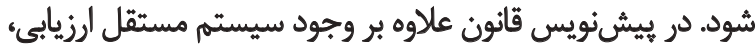

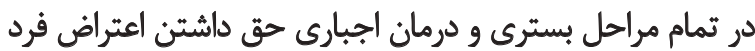

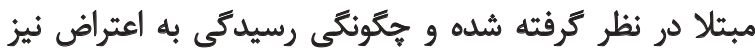

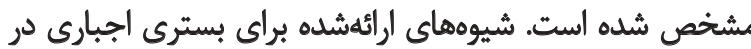

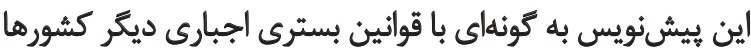

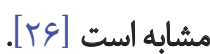

با وجود شباهتهاى اين بيشنويس با قواثين بهداشت روان

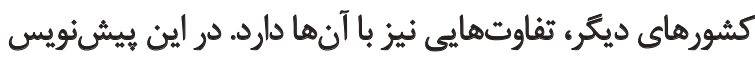

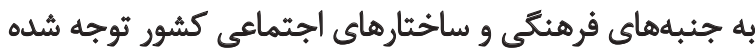

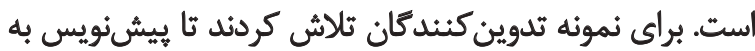

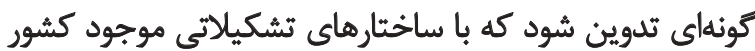

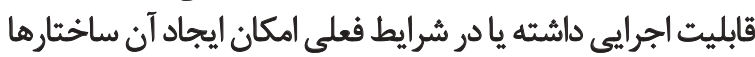

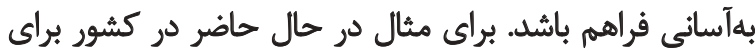

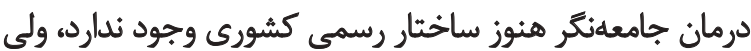

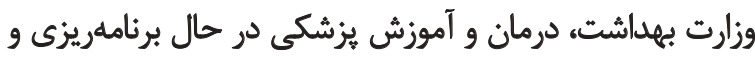


غيردولتى كه بهطور رايخان بيشنويس را مطالعه كردند و نظرات

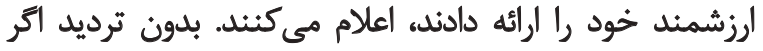

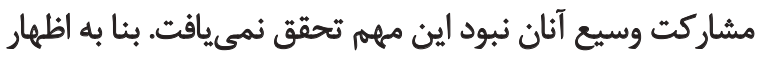

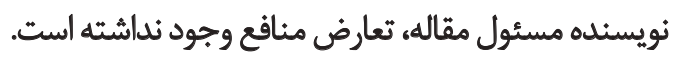




\section{References}

[1] World Health Organization. WHO Checklist on Mental Health Legislation. Geneva: World Health Organization; 2003.

[2] Curran WJ, Harding TW. The Law and mental health: Harmonizing objectives. Geneva: World Health Organization; 1978.

[3] World Health Organization. Mental health atlas. Geneva: World Health Organization; 2005.

[4] World Health Organization. Mental health atlas. Geneva: World Health Organization; 2014

[5] World Health Organization. Mental health care law: Ten basic principles. Geneva: World Health Organization; 1996.

[6] Office of the United Nations High Commissioner for Human Rights. Principles for the protection of persons with mental illness and the improvement of health care. New York: United Nations; 1991.

[7] Davidian, H. [Psychiatry in Iran in the early Islamic civilization (An analytical view) (Persian)]. Iranian Journal of Psychiatry \& Clinical Psychology. 1995; 2(1-2): 7-15.

[8] Moharrary, MR. A Glance at the History of Psychiatry in the World with Special Reference to Iran (Persian)]. Iranian Journal of Psychiatry \& Clinical Psychology. 1994; 1(2-3):27-49.

[9] Rey-Shahri, M. [Wisdom (Arabic)]. Ghom: Matabe'e Markaz AlNashr; 1985.

[10] Abbassi, M. [Consent for treatment (Persian)]. Tehran: Hoghoughi Publication; 2001.

[11] Hojjati Ashrafi, GhR. [The codex of basic - civil laws (Persian)]. Tehran: Ganj-e Danesh Publication. 1997.

[12] Legal Deputy of Presidency. [Civil law (Persian)]. Tehran: Deputy of Codification and Publication of Laws and Regulations; 2014.

[13] Tofighi, H. [Law and psychiatry (Persian)]. Iranian Journal of Forensic Medicine. 1996; 2(7):33-69.

[14] Regional Office for the Eastern Mediterranean. Report on the Intercountry consultation on mental health legislation in different law traditions. Geneva: World Health Organization; 1999.

[15] Shahmohammadi D. [A call for collaboration in preparing the draft of mental health act in Islamic Republic of Iran (Persian)]. Iranian Journal of Psychiatry \& clinical Psychology (Andisheh va Raftar). 2008; 4(4):70.

[16] Asgharzadeh-Amin, S. Shahmohammadi, D, Ehsanmanesh M. [Preliminary study of cultural contents of mentally disordered inpatient's delusions (Persian)]. Iranian Journal of Psychiatry \& Clinical Psychology. 2001; 7(1-2):33-39.

[17] Yadollahi Z, Bolhari J. [The perspectives of Tehran psychiatrists on Iranian mental health laws (Persian)]. Iranian Journal of Psychiatry \& Clinical Psychology. 2004; 10(1-2):44-49.

[18] NSW Institute of Psychiatry. Mental health act guide book. New South Wales: The New South Wales Institute of Psychiatry; 1998.

[19] Mane P, Gandevia Y. Mental health in India: Issues and concerns. Bombay: TATA Institute of Social Sciences; 1993.
[20] Ministry of Health. Guide to the mental health act. London: Ministry of Health; 2005.

[21] Mental Health Coordinating Council. The mental health rights manual: An online guide to the legal and human rights of people navigating the mental health and human service systems in NSW. $4^{\text {th }}$ ed. New South Wales: Mental Health Coordinating Council; 1995.

[22] Law foundation of New South Wales. Mental health rights manual: A guide to the legal and human rights of people with a mental illnessin NSW. New South Wales: Law foundation of New South Wales Publishing; 1995.

[23] Sadock BJ, Sadock VA, Ruiz P. Comprehensive textbook of psychiatry. $9^{\text {th }}$ ed. Philadelphia: Lippincott Williams and Wilkins; 2009.

[24] Academy of Medical Sciences. [Report of the $200^{\text {th }}$ session of the Health and Nutrition Sciences Committee (Persian)]. Tehran: Academy of Medical Sciences.

[25] Academy of Medical Sciences. [Report of the $202^{\text {th }}$ session of the Health and Nutrition Sciences committee (Persian)]. Tehran: Academy of Medical Sciences.

[26] Nasr Esfahani M, Attari Moghadam J, Rasoulian M, Ghalehbandi M, Saberi SM, Samimi-Ardestani S M, et al. [Involuntary treatment and hospitalization: Review of mental health acts (Persian)]. Iranian Journal of Psychiatry and Clinical Psychology. 2008; 14(1):4-16. 
